\title{
Recommendations for invasive procedures in patients with diseases of the liver and biliary tract: report of a joint meeting of the Brazilian Society of Hepatology (SBH), Brazilian Society of Digestive Endoscopy (SOBED) and Brazilian Society of Interventional Radiology and Endovascular Surgery (SOBRICE)
}

\author{
Leonardo de Lucca SCHIAVON1, Flávio Hayato EJIMA², Marcos Roberto de MENEZES², \\ Paulo Lisboa BITTENCOURT ${ }^{4}$, and Members of the Pannel of the 1st Joint Meeting \\ of the SBH, SOBED and SOBRICE*
}

\begin{abstract}
Liver and biliary tract diseases are common causes of morbidity and mortality worldwide. Invasive procedures are usually performed in those patients with hepatobiliary diseases for both diagnostic and therapeutic purposes. Defining proper indications and restraints of commonly used techniques is crucial for proper patient selection, maximizing positive results and limiting complications. In 2018, the Brazilian Society of Hepato$\operatorname{logy}(\mathrm{SBH})$ in cooperation with the Brazilian Society of Interventional Radiology and Endovascular surgery (SOBRICE) and the Brazilian Society of Digestive Endoscopy (SOBED) sponsored a joint single-topic meeting on invasive procedures in patients with hepatobiliary diseases. This paper summarizes the proceedings of the aforementioned meeting. It is intended to guide clinicians, gastroenterologists, hepatologists, radiologists, and endoscopists for the proper use of invasive procedures for management of patients with hepatobiliary diseases.
\end{abstract}

HEADINGS - Minimally invasive surgical procedures. Portal hypertension. Hepatocellular carcinoma. Biliary tract diseases.

\section{INTRODUCTION}

Liver and biliary tract diseases are common causes of morbidity and mortality around the world ${ }^{(1,2)}$. When deaths from cirrhosis, hepatocellular carcinoma (HCC), and acute hepatitis are combined, the annual number of fatalities due to liver disease can exceed two million $^{(3)}$. Even though substantial improvement was seen over the last years, especially in antiviral therapy for hepatitis $C$ infection, the burden of liver disease continues to grow worldwide ${ }^{(1,2)}$. Diseases of the biliary tree such as cholangiocarcinoma (CCC) and primary sclerosing cholangitis (PSC) are also increasingly common and usually represent a challenge for practitioners ${ }^{(4,5)}$. In addition, biliary involvement is frequently seen in other common benign and malignant disorders, particularly choledocolithiasis, chronic pancreatitis and pancreatic cancer.

Invasive procedures are usually performed in patients with hepatobiliary diseases both for diagnostic and therapeutic purposes. Defining proper indications and restraints of commonly used techniques is crucial for proper patient selection in order to achieve the best outcomes and to reduce the risk of procedurerelated complications. In order to discuss recent advances in this field, the Brazilian Society of Hepatology (SBH) in cooperation with the Brazilian Society of Digestive Endoscopy (SOBED) and the Brazilian Society of Interventional Radiology and Endovascular (SOBRICE) sponsored a joint single-topic meeting on invasive procedures in patients with liver and biliary tract, which was held in Brasília on April 2018 to particularly address controversies in the employment of invasive procedures in the management of refractory ascites (RA), hepatorenal syndrome (HRS), portal hypertension $(\mathrm{PH})$ related gastrointestinal bleeding, HCC as well as benign and malignant biliary tract diseases. This paper summarizes the proceedings of the aforementioned meeting with the aim to draw evidence-based recommendations to guide clinicians, gastroenterologists, hepatologists, radiologists and endoscopists for the use of invasive procedures in patients with hepatobiliary diseases. Those recommendations were graded according to the grading system adopted by the American College of Cardiology and the American Heart Association ${ }^{(6)}$, as outlined below:

Declared conflict of interest of all authors: none

Disclosure of funding: no funding received

Corresponding author: Leonardo de Lucca Schiavon. E-mail: leo-jf@uol.com.br

${ }^{*}$ Aírton Mota Moreira ${ }^{5}$, Alberto Queiroz Farias ${ }^{7}$, Aline Lopes Chagas ${ }^{7}$, André Moreira de Assis ${ }^{5,6}$, Ângelo Zambam de Mattos ${ }^{8}$, Bruno Chaves Salomão9 ${ }^{9}$, Carlos Terra ${ }^{10,11}$, Fernanda Prata Borges Martins ${ }^{12}$, Francisco Cesar Carnevale ${ }^{13}$, Guilherme Ferreira da Motta Rezende ${ }^{14}$, Gustavo Andrade de Paulo ${ }^{12}$, Gustavo Henrique Santos Pereira ${ }^{15}$, Joaquim Maurício da Motta-Leal-Filho ${ }^{16}$, Juliana de Meneses ${ }^{2,17}$, Lucas Santana Nova da Costa ${ }^{2,9}$, Marcos de Vasconcelos Carneiro ${ }^{18,19}$, Marcos Roberto de Menezes ${ }^{16}$, Mário Reis Álvares-da-Silva ${ }^{20}$, Mayra Veloso Ayrimoraes Soares ${ }^{9,21}$, Osvaldo Ignácio Pereira ${ }^{13}$, Rafael Oliveira Ximenes ${ }^{22}$, Renata Filardi Simiqueli Durante ${ }^{2}$, Valério Alves Ferreira ${ }^{2,23}$, Vinícius Machado de Lima ${ }^{24}$ 
- Class I: Conditions for which there is evidence and/or general agreement that a given procedure or treatment is useful and effective.

- Class II: Conditions for which there is conflicting evidence and/or a divergence of opinion about the usefulness/efficacy of a procedure or treatment.

- Class IIa: Weight of evidence/opinion is in favor of usefulness/efficacy.

- Class IIb: usefulness/efficacy is less well established by evidence/opinion.

- Class III: Conditions for which there is evidence and/or general agreement that the procedure/treatment is not useful/ effective and in some cases may be harmful.

\section{PART I: REFRACTORY ASCITES}

The International Club of Ascitis (ICA) defined refractory ascites (RA) in the presence of ascites that cannot be mobilized or that recurred shortly ( $<4$ weeks) after large volume paracentesis (LVP), sodium restriction (salt-restricted diet of less than $5.2 \mathrm{~g}$ of salt/day) and intensive diuretic therapy (spironolactone up to 400 $\mathrm{mg} /$ day and furosemide up to $160 \mathrm{mg} /$ day) for at least on week ${ }^{(7)}$ or in the presence of diuretic-intractable ascites due to the occurrence of adverse effects such as hepatic encephalopathy (HE), acute kidney injury (AKI), hyponatremia, hypokalemia, hyperkalemia and intolerable muscle cramps $^{(7)}$. Several challenging complications are commonly seen in patients with RA, such as AKI and HRS, dilutional hyponatremia, hepatic hydrothorax $(\mathrm{HH})$, incarcerated umbilical hernias, spontaneous bacterial peritonitis (SBP) and severe malnutrition ${ }^{(8,9)}$. The six-month survival of patients with $\mathrm{RA}$ is estimated as $50 \%{ }^{(10)}$. Therefore, all patients with refractory ascites, irrespective of their MELD scores, should be considered for liver transplantation (LT).

Different invasive approaches were proposed for the management RA in patients in the waiting list for LT, including peritoneovenous shunts (currently in disuse), LVP and transjugular intrahepatic portosystemic shunt (TIPS). LVP combined with albumin infusion (6-8 g per liter of ascites drained) is effective and safe, and therefore is usually considered the initial approach for patients with $\mathrm{RA}^{(11)}$. TIPS is a procedure that uses imaging guidance to insert a stent connecting a branch of the portal vein to a branch of the hepatic vein, reducing portal pressure. Several randomized controlled trials (RCTs) have compared TIPS vs LVP combined with albumin infusion for treatment of RA. In those trials, the following end-points were considered: survival, ascites control, quality of life and HE. Six studies used uncovered TIPS ${ }^{(12,17)}$ and one used covered stents $^{(18)}$. The ICA definition for RA was employed in the majority of the studies, however three $\mathrm{RCTs}^{(13,15,18)}$ also included patients with recurrent ascites (characterized by frequent requirement of LVP). Patients with advanced liver failure, HE (especially at the time of inclusion or recurrent), portal vein thrombosis (PVT), AKI, and severe comorbidities were generally excluded.

Data extracted from those selected studies indicate that, when compared to LVP plus albumin, TIPS is more effective in the control of ascitis, although with a slightly higher incidence of HE. The survival impact of TIPS was less obvious with RCTs showing conflicting results. In two RCTs, TIPS was associated with improved survival as compared to $\operatorname{LVP}^{(15,17)}$. Other study showed that TIPS was independently related to transplant-free survival ${ }^{(13)}$. On the other hand, two trials failed to show survival benefit from TIPS procedure as compared to LVP plus albumin ${ }^{(14,16)}$. Only one study exhibited improved survival in LVP plus albumin group when compared to TIPS ${ }^{(12)}$. However, the conclusions from this study should be evaluated with caution given that the higher mortality related to TIPS was exclusively observed among Child-Pugh (CP) C patients, a group in which TIPS would be currently contraindicated. Two meta-analyses including the above mentioned RCTs were performed and a transplant-free survival benefit for the TIPS procedure was indicated in one ${ }^{(19)}$, while in the other analysis, this benefit was restricted to patients with recurrent ascites ${ }^{(20)}$. In the single study that compared covered TIPS against LVP plus albumin for treatment of recurrent ascites, TIPS was associated with better control of ascites and higher transplant-free survival, without significant increase in HE rates ${ }^{(18)}$. Although RCTs and meta-analyses exhibited conflicting results regarding survival benefits of TIPS, this procedure is regarded as a useful therapeutic option for patients with RA and should be strongly considered in the absence of contraindications in the following situations: requirement of more than two LVP per month; presence of loculated ascites; patient intolerance for repeated LVP and RA associated with $\mathrm{HH}^{(11)}$. Covered stents are preferred for TIPS procedure as it has shown to improve ascites control and survival, without increasing $\mathrm{HE}$ rates ${ }^{(18)}$.

\section{Recommendations}

a) All cirrhotic patients with RA should be evaluated for liver transplantation (Class I);

b) LVP plus albumin infusion (6-8 g of albumin per liter of ascites removed) can be recommended as first-line treatment for patients with RA (Class IIa); TIPS insertion improves ascites control and should be considered in all patients with RA (Class IIa);

c) The decision to perform TIPS should be individualized considering local expertise and patients characteristics;

d) TIPS should not be performed in subjects with absolute contraindications for the procedure including: advanced liver failure $(C P C \geq 12$, MELD score $\geq 18$, total bilirubin $\geq 5$ $\mathrm{mg} / \mathrm{dL}$, previous or currently hepatic encephalopathy grade $\geq 2$ ), congestive heart failure, severe pulmonary hypertension, unrelieved biliary obstruction, untreated infection or uncontrolled sepsis, and multiple hepatic cysts (Class III);

e) After extensive multidisciplinary discussion involving the patient of estimated risks and expected benefits, TIPS could be employed in the presence of relative contraindications for the procedure, including age of more than 70 years, HCC, non-compliance with sodium restriction diet and portal or hepatic vein thromboses (Class IIb);

f) After assessment of absolute and relative contraindications, patients in the following situations should be strongly considered for TIPS placement: requirement of $>2$ paracenteses per month; presence of loculated ascites; patient intolerance for repeated LVP and RA associated with HH (Class IIa);

g) Covered are preferred over uncovered stents for the TIPS procedure as it has been associated with improved outcomes (Class IIa).

\section{PART II: HEPATORENAL SYNDROME}

HRS is the most severe form of AKI in patients with cirrhosis and ascites. The incidence of HRS among those patients is estimated as $18 \%$ in 1 -year and $39 \%$ in 5 -years ${ }^{(21)}$. HRS is character- 
ized by severe renal vasoconstriction, leading to reduction renal perfusion pressure and decreased glomerular filtration rate (GFR). It determine a markedly decrease in renal ability to excrete sodium and free-water in the absence of significant histological damage to the kidney ${ }^{(22)}$. HRS was once considered the complication of cirrhosis with the worst prognosis ${ }^{(23)}$, but the development of effective therapies capable of reverting the syndrome (infusion of terlipressin or noradrenaline and high-dose albumin) has increased short-term survival, allowing a significant number of patients to undergo LT.

HRS is classically divided in types 1 and 2 by the $\mathrm{ICA}^{(24)}$. HRS type 1 , recently renamed as acute kidney injury-HRS (AKI-HRS), is a rapidly progressive and severe form of AKI, with median survival of fifteen days if left untreated ${ }^{(24-26)}$. Type 2 HRS, now redefined as chronic kidney disease-HRS (CKD-HRS), is a slowly progressive kidney failure with less-marked reduction in GFR and longer survival when compared AKI-HRS ${ }^{(24-26)}$. The major clinical finding of CKD-HRS is RA.

Information on diagnostic criteria and management of AKIHRS are outside the scope of this paper and are discussed in detail in the recently published recommendations of the Brazilian Society of Hepatology for the management of acute kidney injury in patients with cirrhosis ${ }^{(27)}$. This document will focus on the role of invasive procedures for management of AKI-HRS and CKD-HRS.

Evidence for TIPS as a therapeutic option for HRS is scarce as the majority of studies evaluating this issue were small and uncontrolled. One of the largest studies was published in 2000 by Brensing et al. ${ }^{(28)}$. In this study, 41 patients with cirrhosis and HRS (14 with AKI-HRS and 17 with CKD-HRS) were included. TIPS was used in 31 subjects. The other 10 patients were regarded as controls. The mean survival of patients treated with TIPS was significantly higher when compared to controls, even though the control group was comprised by patients with contraindications to TIPS, indicating a more severe liver disease at baseline ${ }^{(28)}$. Other studies, although methodologically limited, also suggested a positive impact of TIPS in renal and circulatory function of patients with AKI-HRS ${ }^{(29-31)}$

Recently, a meta-analysis was published addressing the role of TIPS in the treatment of AKI-HRS and CKD-HRS ${ }^{(32)}$. Nine uncontrolled studies (128 patients) were included. The pooled short-term and 1-year survival rates in patients with AKI-HRS were $72 \%$ and $47 \%$, respectively ${ }^{(32)}$. The pooled short-term and 1 -year survival rates in patients with CKD-HRS were $86 \%$ and $64 \%$, respectively ${ }^{(32)}$. The pooled rate of renal function improvement after TIPS was $83 \%$ in patients with any type of HRS and $93 \%$ in patients with AKI-HRS ${ }^{(32)}$. Renal function parameters, including serum creatinine, blood urea nitrogen, serum sodium, urine sodium excretion, and urine volume, were significantly improved after TIPS $^{(32)}$. The pooled rate of TIPS related complications was $31 \%$ and HE was frequent after TIPS implantation, with a pooled rate of $49 \%$ for all patients ${ }^{(32)}$. The authors concluded that TIPS may provide a potential survival benefit and high rates of renal function improvement in patients with $\mathrm{HRS}^{(32)}$. However, this analysis is significantly limited by the low quality of those included studies. In addition, a high incidence of TIPS-related complications, particularly post-TIPS HE was observed. Therefore, it is important to carefully assess the risks and benefits of the procedure in any individual patient with HRS under evaluation for TIPS. It should be noted that most patients with CKD-HRS would have by definition RA, whose recommendations for invasive procedures have been outlined before in the text.

\section{Recommendations}

a) All patients with AKI-HRS and CKD-HRS should be evaluated for liver transplantation as this modality is considered definitive treatment for those cases (Class I);

b) Given the low quality of evidence available, TIPS cannot be recommended at this time for the treatment of AKI-HRS (Class IIb);

c) TIPS may be considered a therapeutic option for selected cases of CKD-HRS, as it may improve renal function and survival in the context of RA (Class IIb)

\section{PART III: GASTROINTESTINAL BLEEDING RELATED TO PORTAL HYPERTENSION}

Acute variceal bleeding (AVB) is one of the most frequent complications of $\mathrm{PH}$ and is still associated with substantial mortality, despite significant advances observed over the last years. Invasive procedures are commonly recommended in patients with $\mathrm{PH}$ for prophylaxis and therapy of AVB and other PH-related bleeding. In this document, the role of endoscopic and endovascular interventions for primary and secondary prophylaxis of $\mathrm{PH}$ related bleeding, as well as for the management of acute bleeding will be addressed. Details about clinical approach of patients with PH regarding noninvasive therapies are outside the scope of this document and were previously addressed in the paper Variceal Bleeding: Update of Recommendations from the Brazilian Association of Hepatology $\mathrm{y}^{(33)}$.

\section{Prevention of first bleeding from varices (primary prophylaxis)}

Primary prophylaxis is recommended for all patients with medium or large-size esophageal varices, and also for those with small varices with red signs or $\mathrm{CP} \mathrm{C}^{(33)}$. Both endoscopic therapies and pharmacologic approaches with traditional non-selective beta blockers (NSBB) such as propranolol or nadolol, or carvedilol can be used in this setting. A recent meta-analysis of $32 \mathrm{RCT}$ s including 3362 cirrhotic adults with large esophageal varices and no prior history of bleeding showed that endoscopic variceal ligation (EVL) was associated with higher risk of overall mortality when compared to NSBB monotherapy ${ }^{(34)}$. However, EVL alone or in combination with NSBB was associated with a decreased risk of first variceal bleeding when compared to placebo ${ }^{(34)}$ and carvedilol was also shown to be associated with better outcomes when compared to $\mathrm{EVL}^{(35,36)}$. Therefore, either NSBB, EVL or carvedilol could be used for prevention of the first variceal bleeding according local expertise in therapeutic endoscopy and patient characteristics and preferences, taking into consideration particularly the degree of liver dysfunction and the presence of RA or AKI before decision making for pharmacological approaches ${ }^{(32)}$. Propranolol intolerant patients should be switched either to carvedilol or EVL in the presence of compensated cirrhosis or only EVL in subjects with decompensated cirrhosis.

Sclerotherapy, on the other hand, failed to demonstrate efficacy for primary prophylaxis and is currently not recommended in this setting ${ }^{(33,37-39)}$.

Gastric varices $(\mathrm{GV})$ should be categorized according to the Sarin classification, as outlined elsewhere ${ }^{(40)}$. Briefly, gastro-esophageal varices (GOV) type 1 (GOV1) are defined as esophageal varices extending 2-5 cm below the cardia into the lesser curvature of the stomach; GOV type 2 (GOV2) as usually large varices extending 
below cardia into fundus; isolated gastric varices (IGV) type 1 (IGV1) as isolated fundal gastric varices and IGV type 2 as GV elsewhere in the stomach. Ectopic varices are usually described as varices occurring in other parts of the gastrointestinal tract. GOV1 varices are the most common type of gastric varices. Due to the lack of data, they are commonly managed with a similar approach as for esophageal varices ${ }^{(41)}$. Regarding other types of $\mathrm{GV}$, there is only one RCT addressing prevention of first variceal bleeding including patients with large GOV2 and $\mathrm{IGV}^{(42)}$. In this trial, subjects were randomized to endoscopic therapy glue cyanoacrylate) injection, NSBB, or observation ${ }^{(42)}$. Only $15 \%$ of patients had IGV1. Endoscopic therapy with glue injection was associated with lower bleeding rate $(10 \%)$ than NSBBs $(38 \%)$ or no therapy $(53 \%)$. Better survival was also observed in the cyanoacrylate-treated group $(93 \%)$ compared with observation $(74 \%)$, but not when compared to NSBB $(83 \%)$. These positive results indicate that endoscopic therapy with glue injection may be a suitable option for $\mathrm{GV}$ bleeding prevention in patients with large GOV2 or IGV1. However, NSBB treatment is less invasive and may prevent other complications of cirrhosis, remaining the most common therapeutic modality for these patients until more data on endoscopic treatment is available. Other invasive procedures such as TIPS or balloon occluded retrograde transvenous obliteration (BRTO) have not been adequately tested for prevention of the first variceal bleeding ${ }^{(32)}$.

\section{Recommendations}

a) Traditional NSBB, carvedilol or EVL are suitable options for prevention of the first bleeding from esophageal varices (Class I). Therapeutic strategies should be tailored according to the patients characteristics and preferences, presence of contraindications, potential adverse events and availability of local resources and expertise.

EVL or carvedilol could be used in CP A patients intolerant or with contraindications to traditional NSBB, but EVL is preferable to carvedilol in those subjects with more advanced liver dysfunction (Class I).

b) Until more data are available, the recommendations for management of GOV1 varices are the same as for esophageal varices (Class IIb)

c) Traditional NSBB are recommended for prevention of the first variceal bleeding from GOV2, IGV or ectopic varices. (Class IIb) Use of endoscopic glue injection is promising, but its employment still requires more data concerning efficacy and particularly safety.

\section{Treatment of acute bleeding}

AVB should still one of the most challenging complications of cirrhosis and PH. As a result of employment of novel pharmacologic, endoscopic and endovascular approaches, a significant improvement in survival of $\mathrm{PH}$-related bleeding was observed over the last decades ${ }^{(43)}$. Here we will discuss invasive procedures used for controlling acute bleeding. Details about general measures and pharmacologic therapy in this setting can be found at the paper variceal bleeding: update of recommendations from the Brazilian Association of Hepatology ${ }^{(33)}$.

Combination of pharmacologic and endoscopic therapies is the mainstay of treatment in cases of AVB. A meta-analysis of eight RCTs including a total of 939 patients showed that combined therapy is associated with higher rates of control of acute bleeding and lower rebleeding rates ${ }^{(44)}$. Performing EVL in combination with vasoactive drugs proved to be superior to pharmacologic therapy alone in preventing early rebleeding, even in the absence of active bleeding at the time of endoscopy ${ }^{(45)}$.

Both EVL and sclerotherapy showed high efficacy, with rates over $80 \%$ in the control of acute bleeding ${ }^{(46)}$. However, EVL has been associated with a better safety profile and lower mortality when compared to sclerotherapy. A meta-analysis of 10 studies including 467 patients showed superiority of EVL over sclerotherapy regarding control of active bleeding, adverse events, and survival( ${ }^{(47)}$. These worse results observed with sclerotherapy may be at least partially explained by the fact that this injection method has been associated with a sustained increase in portal pressure which was not observed with $\mathrm{VBL}^{(48)}$. More recently, a meta-analysis including 14 studies and a total of 1236 patients also showed that EVL was better than sclerotherapy in terms of the lower rates of rebleeding, complications, and the higher rate of variceal eradication, even though no differences were observed regarding survival ${ }^{(49)}$.

Recently, the use of early TIPS in selected patients with AVB has been advocated. The most important study evaluating the strategy of early TIPS included 63 cirrhotics with acute variceal bleeding and high risk of treatment failure (Child-Pugh C up to 13 points or Child-Pugh B plus active bleeding at endoscopy) that were randomized to receive early TIPS, using expanded polytetrafluoroethylene (ePTFE)-covered stents in the first $72 \mathrm{~h}$ or current standard of care ${ }^{(50)}$. Early TIPS was associated better control of bleeding, lower incidence of ascites, and an improvement in survival without increasing the incidence of hepatic encephalopathy ${ }^{(50)}$. These results were confirmed in an observational retrospective study including 75 patients (45 treated with early TIPS $)^{(51)}$, suggesting that early TIPS is beneficial in selected patients with acute variceal bleeding and high risk of treatment failure.

There are few data regarding treatment of acute bleeding from GV. Efficacy of variceal obliteration with glue injection (cyanoacrylate) has been addressed in three randomized trials ${ }^{(52-54)}$. Two trials showed superiority of cyanoacrylate in bleeding control as compared to sclerotherapy (alcohol injection) ${ }^{(53)}$ and EVL ${ }^{(52)}$, and one trial showed similar results for glue injection and EVL ${ }^{(54)}$. Rebleeding rates were significantly lower in cyanoacrylate treated patients when compared to EVL ${ }^{(52,54)}$. Although both EVL or cyanoacrylate injection seem to be good options for gastroesophageal varices type 1 (GOV1), endoscopic therapy with glue injection is recommended for acute bleeding from IGV and GOV2 that extend beyond the cardia ${ }^{(41)}$. Similarly, patients bleeding from IGV were excluded from the early TIPS trial and, therefore, this strategy cannot be recommended for these cases at this time ${ }^{(50)}$.

In cases of persistent bleeding or early rebleeding from esophageal or gastric varices, TIPS should be considered as the rescue therapy of choice. This procedure managed to achieve control of bleeding in $90 \%$ to $100 \%$ of cases, with rebleeding rates of $6 \%$ to $16 \%{ }^{(55,56)}$. Balloon tamponade may be necessary in patients with massive variceal haemorrhage or refractory bleeding as a bridge to more definitive therapy ${ }^{(41)}$. Self-expandable, esophageal covered metal stents (SX-ELLA Danis) appears to be as effective as balloon tamponade in control of bleeding in refractory cases of esophageal variceal bleeding, with a better safety profile $e^{(41,43,57)}$.

\section{Recommendations}

a) Combination of pharmacologic (vasoactive drugs) and endoscopic therapies should be performed in patients with acute variceal bleeding (Class I). Endoscopic therapy 
should be employed in patients with suspected variceal bleeding even in the absence of active bleeding at the time of endoscopy (Class I).

b) EVL is superior to sclerotherapy in the treatment of acute esophageal variceal bleeding in terms of the lower rates of rebleeding and complications, and therefore should be the treatment of choice (Class I). Sclerotherapy is an option when VBL is unavailable or technically not feasible (Class IIa).

c) If available, early TIPS placement in cases of bleeding from esophageal varices, GOV1 or GOV2 can be considered for high-risk patients (Child-Pugh C with 10-13 points or ChildPugh B with active bleeding) after initial endoscopic and pharmacologic therapy (within 72h) (Class IIa). However, refinement of the criteria used to select patients for early TIPS is needed before it can be routinely recommended.

d) Bleeding from GOV1 can be managed similarly to esophageal varices (Class IIb). Both EVL and endoscopic glue injection can be recommended in this case (Class IIb).

e) Endoscopic glue injection is the preferred treatment of bleeding caused by GOV2 and IGV1 (Class I).

f) TIPS should be considered as the rescue therapy of choice for cases of persistent bleeding or early rebleeding from both esophageal or GV (Class I). Additional endoscopic hemostasis could also be attempted while waiting for TIPS placement, if it is not immediately available (Class IIb).

g) Balloon tamponade or self-expandable esophageal covered metal stents (SX-ELLA Danis) should be used as a bridge to more definitive therapy in cases of massive or refractory bleeding (Class I). Although both therapies are effective in stop bleeding, self-expandable, esophageal covered metal stents appear to be safer.

\section{Prevention of rebleeding (secondary prophylaxis)}

Patients who recover from the first episode of variceal bleeding have a high rebleeding risk and, therefore, should be considered candidates for secondary prophylaxis ${ }^{(33,41)}$. For patients treated with TIPS in AVB, no specific therapies for portal hypertension or varices are recommended at this time. Patency of TIPS should be accessed by Doppler ultrasound at least every six months ${ }^{(58)}$. For the majority of other cases (esophageal varices), the recommended approach is combining EVL with NSBB. A meta-analysis of five studies including 476 patients showed that this combination therapy was superior to EVL alone in preventing recurrent bleeding ${ }^{(59)}$. However, the addition of EVL to NSBB (combined with isosorbide mononitrate in this case) exhibited a non-significant decrease of rebleeding rate with no effect on mortality ${ }^{(59)}$. This data indicates that NSBB are the most important component of combination therapy and, if not tolerated, alternative strategies such as TIPS should be considered.

For patients who fail combination therapy with EVL and NSBB, TIPS is considered the treatment of choice, although data are scarce. A trial comparing TIPS with endoscopic therapy (glue injection) plus NSBB for prevention of bleeding (first or second episode of gastric and/or esophageal variceal bleeding) showed that TIPS was associated with lower rebleeding rate, with no differences in survival and with higher incidence of $\mathrm{HE}^{(60)}$. Another RCT showed that TIPS was associated with lower rebleeding rates than hepatic venous pressure gradient measurement-guided pharmacologic therapy. In this study, no differences were observed in survival and TIPS was related to a higher incidence of $\mathrm{HE}^{(61)}$.
Data is also very limited for prevention of rebleeding from gastric varices. A RCT including 67 patients with GOV2 or IGV1 varices who were randomized for NSBB or glue injection showed that the endoscopic therapy was associated with lower rebleeding rates and improved survival ${ }^{(62)}$. Another trial investigating the role of NSBB in patients with GOV2 or IGV1 as an adjunct therapy to glue injection showed no benefit for $\mathrm{NSBB}^{(63)}$. However, these trials included a limited number of patients. In addition, NSBB use in patients with cirrhosis may be associated with other benefits other than prevention of bleeding. TIPS was evaluated, in comparison to glue injection, in a trial including 72 patients with previous hemorrhage from GOV1 or GOV2 ${ }^{(64)}$. In this study, TIPS was associated with significantly lower rates of rebleeding, however, without impact in survival ${ }^{(64)}$.

Balloon-occluded retrograde transvenous obliteration (BRTO) has recently emerged as an option for treatment of gastric varices. BRTO is a procedure for treatment of fundal varices associated with a large gastro-splenorenal collateral and several variations of the technique exist ${ }^{(58)}$. In summary, the procedure involves catheterization of the gastrorenal collateral via the left renal vein using transjugular or transfemoral renal route, under fluoroscopic guidance, with obliteration of gastric varices with sclerosants or coils after occlusion of the collateral by balloon inflation ${ }^{(58)}$. Although BRTO has the theoretical advantage over TIPS of not diverting portal blood flow from the liver, this procedure might increase portal pressure and might worsen other complications, such as ascites or bleeding from esophageal varices. BRTO can be used in patients at high risk for TIPS, such as elevated MELD score (>18), right-sided heart failure, or $\mathrm{HE}^{(65)}$. The major contraindication to BRTO is a portal or splenic vein thrombosis without other portosystemic collaterals to provide adequate mesenteric or splenic venous outflow following BRTO $^{(65)}$. Relative contraindications include lack of gastrorenal shunt, although some specialized centers are currently performing BRTO via nontraditional shunts ${ }^{(65)}$. Data regarding BRTO for prevention of rebleeding from gastric varices are predominantly from uncontrolled studies. A meta-analysis of four cohort studies and one RCT showed that, as compared to TIPS, BRTO was associated with lower a rebleeding rate and a lower incidence of $\mathrm{HE}^{(66)}$. Although very limited by the quality of studies involved, this meta-analysis indicated that BRTO may be considered at least an option to TIPS for patients with previous bleeding from gastric varices ${ }^{(66)}$.

Endoscopic ultrasound (EUS)-guided coil embolization is a therapeutic option for treating gastric varices that involves the placement of micro-coils into the varices leading to obliteration ${ }^{(67)}$. There are data from uncontrolled studies and case reports indicating that EUS-guided coil embolization alone or in combination with glue injection can be used for treatment of gastric and ectopic varices ${ }^{(67)}$. However, these studies are very limited and, at this time, no recommendation can be made on EUS-guided coil embolization for prevention of rebleeding from gastric varices. Given the paucity of data on treatment of ectopic varices, EUS-guided coil embolization alone or in combination with glue injection may be considered only in selected patients with ectopic varices after a careful evaluation of other available therapeutic options.

\section{Recommendations}

a) No specific therapies for PH or varices are recommended for patients treated with early TIPS for AVB (Class III), but shunt patency should be assessed by Doppler ultrasound at least every six months (Class IIb). 
b) Combination of traditional NSBB and EVL is recommended for prevention of recurrent variceal bleeding in patients with cirrhosis not treated with early TIPS (Class I).

c) TIPS is recommended for prevention of rebleeding from esophageal varices in patients who fail combination therapy with EVL and NSBB (Class I).

d) Combination of NSBB and endoscopic therapy (EVL or glue injection) is the first-line therapy to prevent rebleeding from GOV1 (Class I).

e) Endoscopic glue injection with or without NSBB, TIPS and BRTO are options for prevention of rebleeding from GOV2 or IGV1 (Class IIb) according to local expertise availability, patients characteristics and preferences. These methods have not gained widespread application due to availability, cost and also scarcity of data supporting their employment.

f) There are insufficient data to draw evidence-based recommendations for control of bleeding and prevention of rebleeding from IGV2 and ectopic varices, but endoscopic glue injection, EVL, EUS-guided coil embolization alone or in combination with cyanoacrylate, TIPS or BRTO may be considered as therapeutic options (Class IIb).

\section{PART IV: HEPATOCELLULAR CARCINOMA}

HCC accounts for $85 \%-90 \%$ of primary malignant tumors of the liver. Its global incidence is estimated as 500,000 to $1,000,000$ new cases per year and HCC is responsible for 700,000 deaths yearly worldwide ${ }^{(68)}$. $\mathrm{HCC}$ is the most common complication leading death in patients with compensated cirrhosis ${ }^{(69,70)}$. The major therapeutic goal in HCC is to increase survival with good quality of life, and the choice of therapy is based on the stage of the tumor. Staging of $\mathrm{HCC}$ is a complex task that should take into account tumor burden (number, size and location of HCC nodules; presence of vascular invasion and extrahepatic metastases); liver function assessed by $\mathrm{CP}$ classification and clinically significant $\mathrm{PH}$ and presence of patients functional status (evaluated by the Eastern Cooperative Oncology Group Performance Status scale (ECOG-PS) ${ }^{(71,72)}$. The most commonly used staging system for HCC in western countries is the Barcelona Clinic Liver Cancer (BCLC) classification, that is suit especially for subjects candidates for invasive therapeutic interventions ${ }^{(72,74)}$. The most used staging system for HCC in western countries is the Barcelona Clinic Liver Cancer Group (BCLC) classification that is useful to guide management of patients with HCC according to tumor stage and prognosis (FIGURE 1). Most of the

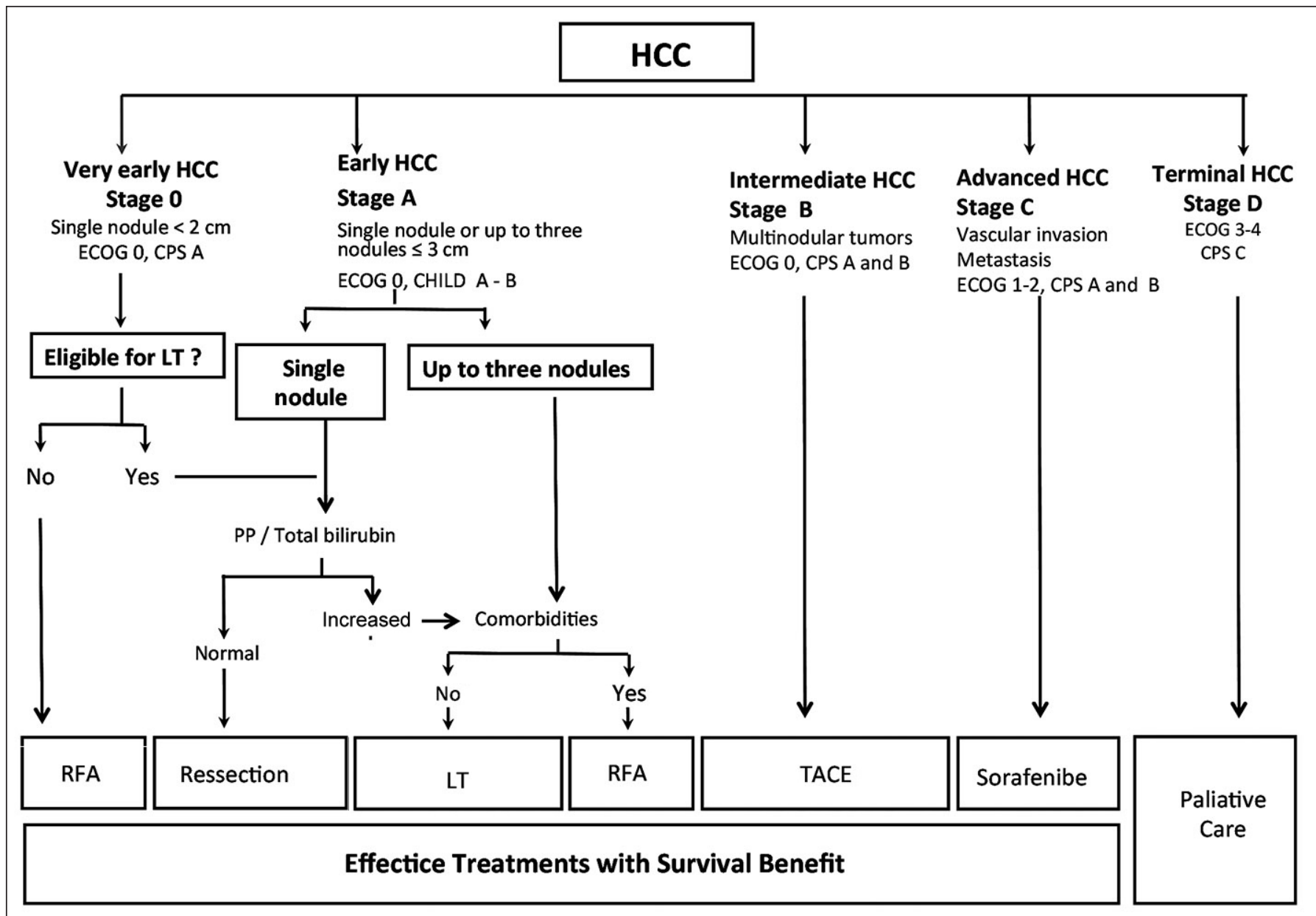

FIGURE 1. Barcelona Clinic Liver Cancer Group (BCLC) algorithm for staging and treatment of hepatocellular carcinoma (HCC).

ECOG: Eastern Cooperative Oncology Group Performance Status scale; CPS: Child-Pugh score; RFA: radiofrequency ablation; LT: liver transplantation; TACE: trascatheter arterial chemoembolization. Adapted from Forner A, Reig M and Bruix J, Lancet, 2018. 
data concerning surgery, LT, locoregional treatments and systemic chemotherapy used the aforementioned BCLC staging system.

This paper will address the role of invasive procedures in the treatment of $\mathrm{HCC}$ according to BCLC classification. Other treatment modalities are reviewed elsewhere ${ }^{(72)}$. Locoregional treatments are usually divided as percutaneous ablative therapies and image-guided transcatheter therapies. Objective responses to those locoregional therapies have been evaluated using the modified Response Evaluation Criteria In Solid Tumours (mRECIST), as this classification was shown to predict survival ${ }^{(73,75,76)}$.

\section{Percutaneous ablative therapies}

The most frequently employed ablative techniques for HCC are radiofrequency ablation (RFA) and percutaneous ethanol injection (PEI) which are usually suitable for BCLC 0 and A patients with HCC. Other different modalities, including microwave ablation, laser ablation, cryoablation, and high-intensity focused ultrasound are not yet readily available and lack robust data for its routine recommendation. Therefore, they will not be discussed in this paper. RFA is performed by placing a needle electrode directly into the tumor with imaging guidance, most often with ultrasonography. It leads to a thermal injury to the tissue through electromagnetic energy deposition ${ }^{(77)}$. PEI is performed by the injection of absolute alcohol through a needle placed percutaneously directly into the tumor under ultrasonographic guidance. Ethanol diffuses into tumor cells and causes dehydration and protein denaturation, resulting in coagulative necrosis. This is usually followed by microvascular thrombosis and subsequent tumor ischemia ${ }^{(78)}$. The major disadvantage of PEI over RFA is that it may be difficult to obtain an adequate ablative margin with the former technique.

Several meta-analyses showed that RFA is superior to PEI regarding overall survival (OS), disease-free survival, and recurrence rates ${ }^{(79-81)}$. However, the size of the tumor appears to be important when indicating percutaneous ablative therapies. For tumors $\leq 2 \mathrm{~cm}$, both RFA and PEI reaches high rates of complete tumor necrosis and can interchangeably, especially when RFA is not technically feasible ${ }^{(73,79)}$. On the other hand, local recurrence rates of up to $49 \%$ were described in cases of $\mathrm{HCC}>2 \mathrm{~cm}$ treated with PEI. RFA is clearly a better choice for tumors between 2 and $3 \mathrm{~cm}^{(79)}$. Complete ablation has been demonstrated in over $95 \%$ of the patients with tumors bellow $5 \mathrm{~cm}$ treated with $\mathrm{RFA}^{(82)}$, even though the optimal candidates are those with lesions $<3$ $\mathrm{cm}$, especially patients with a single nodule $<2 \mathrm{~cm}$ and with the following characteristics: Child-Pugh A, albumin-bilirubin score 1 , and alpha-fetoprotein $<20 \mathrm{ng} / \mathrm{mL}^{(73,83)}$. Although combination of percutaneous ablative modalities with other techniques, such as transcatheter arterial chemoembolization (TACE), is showing promising results (especially in cases of tumors between 3 and 5 $\mathrm{cm}$ ), evidence of benefit is restricted to retrospective studies and RCTs with important selection bias ${ }^{(82)}$. Therefore, more data are necessary before any recommendation regarding combination therapy of either PEI or RF with TACE.

A Cochrane review of four trials including 574 patients compared RFA with surgical resection as fist-line treatment for patients with small, solitary $\mathrm{HCC}^{(84)}$. There was no evidence of a difference in all-cause mortality between surgery and RFA in people eligible for surgery, even though $\mathrm{HCC}$ recurrence was lower in the surgery group and adverse events were less frequent in $\mathrm{RFA}^{(84)}$. Also, RFA was shown to be more cost-effective than resection for very early HCC (single nodule $<2 \mathrm{~cm}$ ) in Child-Pugh A patients and in the presence of two or three nodules $\leq 3 \mathrm{~cm}^{(85)}$. For single HCCs of $3-5 \mathrm{~cm}$, resection provided better life-expectancy and was more cost-effective than $\mathrm{RFA}^{(85)}$.

Location is very important in decision making between resection or RFA. For tumors located centrally in the liver that usually require large resections, RFA is favored, even though proximity with vascular and biliary structures might be a problem. Relative contraindications to RFA include tumor adjacent to large vessels, extrahepatic organs or the liver capsule. Absolute contraindications for RFA include tumors adjacent to large bile ducts, decompensated cirrhosis, history of recent cirrhosis decompensation, such as large ascites, AVB and HE, as well as a CP score $\geq \mathrm{B} 9^{(82)}$.

\section{Recommendations}

a) RFA is the therapeutic modality of choice for patients with HCC BCLC 0 or A unsuitable for surgery (Class I).

b) In very-early HCC (BCLC 0 ) in a favorable location, RFA can be considered the first-line therapy even for candidates for surgical resection (Class IIa).

c) For tumors between 2 and $3 \mathrm{~cm}$ in candidates for surgical resection, RFA might be considered as an alternative to surgery depending on the location of the tumor and on the clinical condition of the patient (Class IIb).

d) In very early (BCLC 0) and early (BCLC A) HCC, PEI is recommended when RFA is not technically feasible, especially for tumors $<2 \mathrm{~cm}$ (Class I). However, for tumors $>2 \mathrm{~cm}$, PEI should be discouraged due to its association with higher rates of incomplete response and local tumor recurrence.

\section{Image-guided transcatheter therapies}

Image-guided transcatheter therapies are intended to induce tumor necrosis relying on the fact that $\mathrm{HCC}$ has a predominant arterial vascularization compared to the rest of the liver parenchyma. This difference in vascularization allows a selective intravascular administration of drugs, embolic particles, or radioactive devices to achieve therapeutic responses ${ }^{(86)}$. Transarterial therapies for HCC include the embolization of microparticles without a chemotherapy agent, bland transarterial embolization (TAE) or with a chemotherapy agent (usually doxorubicin or cisplatin) when it is called transarterial chemoembolization (TACE) ${ }^{(86)}$. In the conventional TACE (cTACE), embolization is performed with particles or lipophilic agents coupled with local injection of the cytotoxic agents ${ }^{(87)}$. More recently, embolization with drug-eluting beads (DEB-TACE) was introduced as an alternative to cTACE, aiming to improve outcomes and decrease side effects. DEB-TACE is based on the use of microspheres that exploit ionic bonds and are able to actively sequester and then slowly release the cytotoxic drug inside the target lesion ${ }^{(87)}$. Another technique that employs a different approach is the transarterial radioembolization (TARE). This technique consists of the selective intra-arterial administration of microspheres loaded with a radioactive compound (usually Yttrium ${ }^{90}$ ). It exerts its therapeutic effect through the radiation carried by these microspheres ${ }^{(88)}$.

cTACE is nowadays the most employed transcatheter therapy used in the treatment of HCC. Although initial studies showed controversial results about survival benefits of cTACE, a metaanalysis of 14 studies showed that cTACE improves survival of patients with unresectable $\mathrm{HCC}^{(89)}$. Although cTACE is not considered a curative treatment, it is the modality of choice for patients with compensated cirrhosis and intermediate HCC (BCLC $\mathrm{B})$ with a favorable performance status (ECOG-PS 0$)^{(73)}$. cTACE is 
also an alternative locoregional treatment for patients with early HCC (BCLC A) with contraindications or to RFA or PEI or in centers where percutaneous ablative treatments are unavailable of $^{(73)}$. Contraindications to TACE are shown in FIGURE $2^{(73,86,90)}$. DEB-TACE was launched as an alternative to cTACE and, although there is a strong rationale for the use of DEB-TACE, evidence for superiority of this strategy over cTACE is scarce. A meta-analysis of 12 studies including 1449 patients found no superiority for DEB-TAVE over cTACE ${ }^{(91)}$. Most comparative studies showed no advantage of DEB-TACE regarding survival and clinical outcomes ${ }^{(87)}$. Results are conflicting regarding safety profile of DEB-TACE in comparison to cTACE. Even though the previously mentioned meta-analysis found no differences regarding survival or frequency of adverse events, some trials reported lower incidence of liver toxicity, doxorubicin-related side effects, postprocedural abdominal pain and overall adverse events in $\mathrm{HCC}$ larger than $5 \mathrm{~cm}$ in BCLC-B patients ${ }^{(92-94)}$. At this time, there are insufficient data to recommend DEB-TACE over cTACE and the choice of technique should be based in availability, local expertise, patients characteristics and physician preferences.

TARE or selective internal radiation therapy (SIRT) consists of arterial infusion of radioactive substances, usually 131-Iodinelabelled lipiodol or microspheres containing yttrium-90. It is a complex treatment that requires multidisciplinary collaboration. Initially, patients are submitted to an hepatic angiography and embolization of extrahepatic branches if necessary. In the same procedure, an arterial injection of 99Tc macroaggregated albumin followed by macroaggregated albumin single-photon emission CT imaging are performed to evaluate the tracer distribution, shunts and for dose calculation ${ }^{(73)}$. One or two weeks later, TARE candidates are readmitted to perform the radioembolization procedure. Given the low embolic effect of the radioactive substances used, the procedure can be performed in patients with portal vein thrombosis ${ }^{(95)}$. Contraindications of TARE are exhibited in FIGURE $3^{(96-99)}$. The median survival time

\begin{tabular}{|c|}
\hline Relative contraindications \\
\hline $\begin{array}{c}\text { - Tumour burden }>50 \% \text { of total liver volume or large tumors }(>10 \mathrm{~cm}) \\
\cdot \text { Biliary-enteric anastomosis or biliary stent } \\
\cdot \text { Severe comorbidities that compromise organ function } \\
\cdot \text { Biliary dilatation } \\
\text { - Allergy to iodine contrast: desensitization can be used in these cases } \\
\cdot \text { Untreated varices at high risk of bleeding }\end{array}$ \\
\hline Absolute contraindications \\
\hline $\begin{array}{c}\bullet \text { Child-Pugh C or Child-Pugh B decompensated cirrhosis }{ }^{1} \\
\bullet \text { Macrovascular invasion of the main portal branches or the main portal vein } \\
\bullet \text { Impaired portal vein blood flow (portal vein thrombus }{ }^{2} \text { or hepatofugal blood flow) } \\
\text { - Technical contraindications to hepatic intra-arterial treatment (e.g., untreatable arterio-venous fistula) } \\
\bullet \text { Renal insufficiency (creatinine } \geq 2 \mathrm{mg} / \mathrm{dL} \text { or creatinine clearance } \leq 30 \mathrm{~mL} / \mathrm{min} \text { ) }\end{array}$ \\
\hline
\end{tabular}

FIGURE 2. Relative and absolute contraindications to transarterial chemoembolization (TACE).

\section{Relative contraindications}

- $\mathrm{ECOG} \geq 2$

- Infiltrative tumors

- Tumor involving more than $50 \%$ of the liver

- Transaminases higher than 5 times the upper limit of normal

- Bilirubin levels $>2 \mathrm{mg} / \mathrm{dL}$

\begin{tabular}{|c|}
\hline Absolute contraindications \\
\hline $\begin{array}{c}\text { Child-Pugh C or Child-Pugh B } \geq 9 \text { points } \\
\bullet \text { Decompensated cirrhosis or history of recent decompensation } \\
(\text { e.g., tense ascites, variceal bleeding, hepatic encephalopathy) } \\
\bullet \text { Uncorrectable shunt to the gastrointestinal tract }\end{array}$ \\
$\begin{array}{c}\text { Lung shunting }>20 \% \text { (resin microspheres) or estimated radiation dose to the } \\
\text { lungs }>30 \text { Gy with a single administration or cumulative dose of } 50 \text { Gy }\end{array}$ \\
\hline Modified from: Venkatanarasimha N, Gogna A, Tong KTA, et al. Clin Radiol 2017.
\end{tabular}

FIGURE 3. Relative and absolute contraindications to transarterial radioembolization (TARE). 
for patients treated with TARE with HCC at intermediate stages is 16.9 months to 17.2 months, and for patients at advanced stages with portal vein invasion is 10 to 12 months $^{(73,100-102)}$. Liver-related toxicity and treatment-related deaths are observed, respectively, in $20 \%$ and $3 \%$ of the patients ${ }^{(101)}$. There are no large-scale prospective RCTs comparing TARE and TACE. Most studies evaluating TARE included patients with more advanced disease with severe tumor burden or portal vein thrombosis as compared to TACE. In a meta-analysis of eight studies including 1499 patients with unresectable HCC, TARE showed similar tumor response rates, with a better safety profile and overall survival as compared to $\mathrm{TACE}^{(103)}$. As TARE is frequently recommended for patients with locally advanced HCC, this procedure was compared to sorafenib in two trials ${ }^{(104,105)}$. In these studies, no differences in overall survival were observed between the two treatment strategies, even though tumor response rates were significantly higher with TARE. In both trials, TARE was associated with less grade $\geq 3$ adverse events as compared to sorafenib ${ }^{(104,105)}$. These studies indicate that TARE may be considered a good option for patients with locally advanced HCC, although further data may help to identify the subgroup of patients in whom a greater benefit of this therapeutic modality is expected.

\section{Recommendations}

a) CTACE is the treatment of choice for patients with intermediate stage HCC (BCLC B) (Class I).

b) TACE can be used as an alternative locoregional treatment for patients with early HCC (BCLC A) with contraindications to RFA/PEI or in centers where percutaneous ablative therapies are not available (Class IIa).

c) There are insufficient data to recommend DEB-TACE over cTACE and the choice of technique should be based in availability, local expertise, patients characteristics and physician preferences (Class IIb).

d) TACE should not be used in patients with decompensated cirrhosis, advanced kidney dysfunction, macrovascular invasion, and extrahepatic spread (Class III).

e) TARE is a promising therapeutic option for HCC with a good safety profile. However, there are insufficient data do recommend TARE over TACE for patients with intermediate HCC or to recommend TARE over Sorafenib for patients with advanced (BCLC C) HCC. The subgroup of patients that will benefit of TARE should be defined (Class IIb).

f) Response to locoregional therapies should be evaluated by the modified Response Evaluation Criteria In Solid Tumours (mRECIST) (Class I).

\section{PART V: BILIARY TRACT DISEASE}

Biliary strictures can be due to different benign or malignant disorders and are a common cause of cholestasis and cholangitis. Proper diagnosis and management are usually multidisciplinary and can be challenging in daily practice. Even though diagnostic aspects of biliary tract diseases are outside the scope of this paper, every effort should be made in establishing a precise diagnosis, especially the differential diagnosis between benign and malignant biliary stricture, since prognosis and therapeutic interventions can vary significantly. This document will address interventional approaches to biliary tract diseases that will be divided in four categories: malignant biliary strictures, benign biliary stricture including strictures after LT and dominant strictures in primary sclerosing cholangitis (PSC).

\section{Malignant biliary stricture}

The most common causes of malignant biliary obstruction are pancreatic adenocarcinoma and CCC. Other malignant neoplasms that can lead to biliary obstruction include ampullary carcinoma, duodenal adenocarcinoma, pancreatic neuroendocrine tumors and obstruction secondary to malignant lymphadenopathy usually due to lymphoma or metastatic disease ${ }^{(106)}$. Although curative surgical resection is the ultimate therapeutic goal, this approach is possible only in a minority of those patients as the most common malignancies leading to biliary obstruction are commonly diagnosed at an advanced stage. Relief of biliary obstruction can alleviate symptoms and prevent complications such as bacterial cholangitis. Over the last years, significant advances were observed in the field of therapeutic endoscopy and interventional radiology for management of malignant biliary strictures. As location of biliary stricture is crucial to guide interventions in these cases, here we will discuss distal and hilar malignant biliary obstructions separately. Other features of the disease, including the possibility of resection, presence of current bacterial cholangitis, and life expectancy are also important and should be considered for proper management.

The most common cause of distal malignant biliary obstruction is advanced pancreatic cancer ${ }^{(106)}$. Distal CCC, although less common, usually has similar presentation to pancreatic adenocarcinoma $^{(106)}$. In a trial including 202 patients with resectable pancreatic cancer, preoperative biliary drainage with stents was associated with increased risk of complications compared to surgery alone ${ }^{(107)}$. Other studies also showed increased risk of complications in patients submitted to preoperative biliary drainage $^{(108-110)}$. However, a meta-analysis of 26 studies including 2230 patients showed that preoperative biliary drainage was associated with less major adverse events as compared to surgery ${ }^{(111)}$. Given these conflicting results, in patients with resectable disease, surgery should be prioritized. Endoscopic or percutaneous stenting should therefore be restricted to patients with bacterial cholangitis, subjects considered for neoadjuvant therapy or in cases of delayed surgery ( $>3$ weeks). For patients with distal malignant biliary obstruction with locally advanced disease who will be candidates for neoadjuvant therapy, biliary stenting is usually employed to relief symptoms during chemoradiotherapy until the time of surgery. Endoscopic retrograde cholangiopancreatography (ERCP) is the usual approach for patients with distal malignant biliary obstruction. The choice of stent will depend on several factors and is summarized summarized in FIGURE 4. In candidates for surgical resection in whom drainage is required, plastic stents are the usual choice as it provides similar short-term results $(<1$ month) to self-expanding metal stents (SEMS) ${ }^{(112)}$. If surgical resection is uncertain or in cases of neoadjuvant therapy, plastic as well as short intrapancreatic or covered SEMS may be used, with a preference for SEMS in patients who are candidates for neoadjuvant therapies ${ }^{(106,112-115)}$. For palliative treatment, a recent meta-analysis showed that, as compared to plastic stents, SEMS are associated with longer stent patency and duration of symptomatic improvement, less late complications, and less reinterventions without impact in overall survival ${ }^{(116)}$. However, SEMS seems to be less cost-effective in patients with life expectancy lower than four months ${ }^{(114)}$. In those cases, the use of plastic stents are warranted ${ }^{(112)}$. 


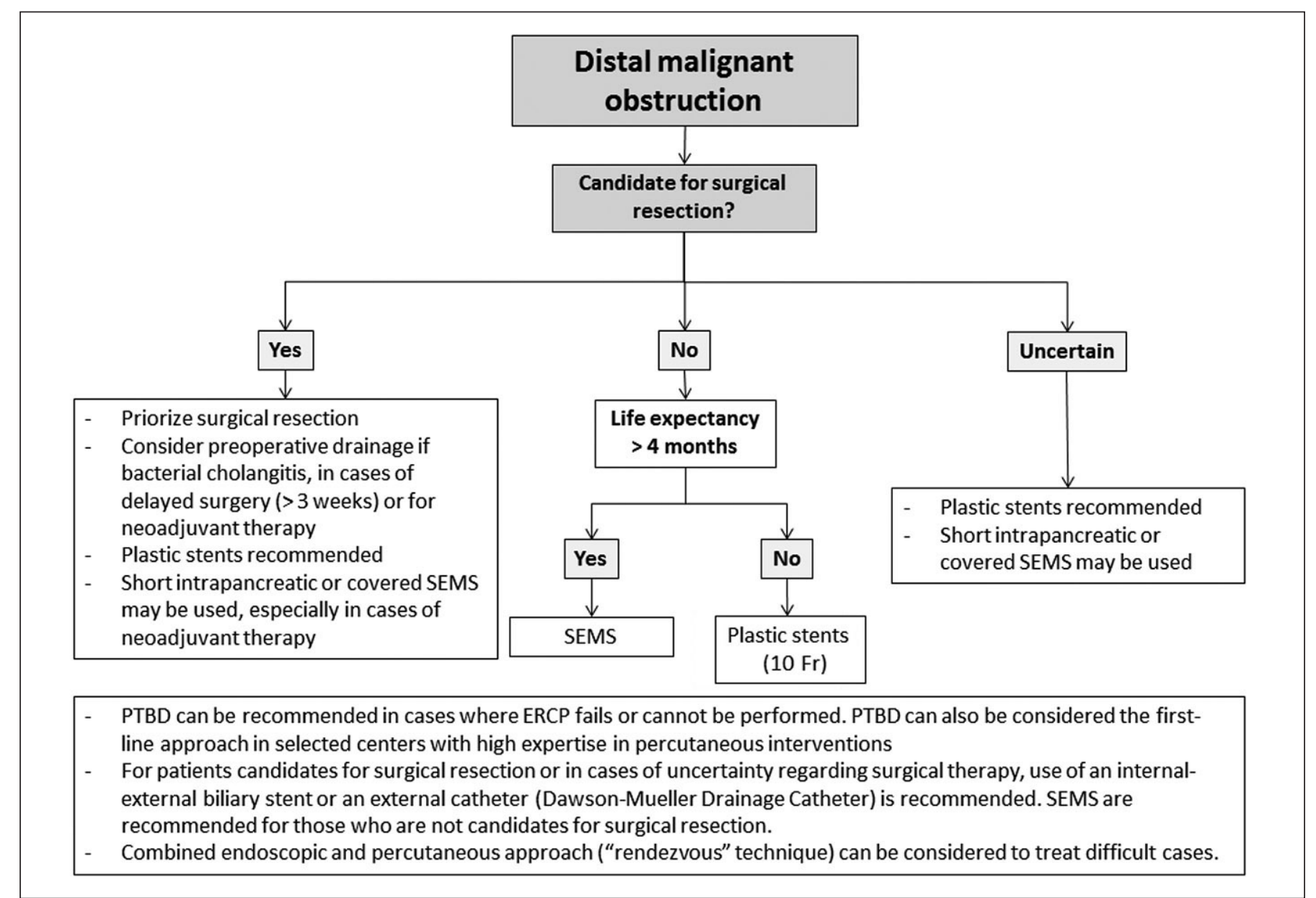

FIGURE 4. Suggested approach to distal malignant obstruction.

Percutaneous transhepatic biliary drainage (PTBD) has been used for both internal and/or external drainage in cases where ERCP fails or cannot be performed. There are meta-analyses showing positive results for PTBD as compared to ERCP for patients with malignant biliary obstruction. However, the results of these meta-analyses are limited due to significant heterogeneity across the studies and the limited data available specifically on the management of distal malignant biliary obstruction ${ }^{(117,118)}$. Therefore, PTBD at this time could be considered as a suitable option to the endoscopic approach in cases of distal malignant tumors, particularly in selected centers with high expertise in percutaneous interventions.

The most frequent etiology of malignant hilar biliary obstruction is CCC. Malignant obstructions at the liver hilum is usually more difficult to treat, and although surgical resection is the only curative option for CCC, most patients present in advances stages of disease and are not candidates for curative treatment ${ }^{(119,120)}$. The Bismuth-Corlette classification system (FIGURE 5) provides an anatomic description of the tumor location and its longitudinal extension into the biliary tree and is recommended in clinical practice to guide therapy ${ }^{(121)}$. Briefly, in this system, hilar cholangiocarcinoma can be classified as follows: a) Type I-tumor involves hepatic bile duct only; b) Type II - tumor involves bile duct bifurcation; c) Type IIIa - tumor involves bile duct burfication and right hepatic bile duct; d) Type IIIb - tumor involves bile duct burfication and left hepatic bile duct; e) Type IV - tumor involves both sides of hepatic bile ducts. Similarly to the approach for distal malignant disease, patients with hilar malignant obstruction that are surgically treatable must have the definitive treatment prioritized. Preoperative drainage is recommended in cases of bacterial cholangitis and can also be considered to alleviate symptoms in cases of delayed surgery. Otherwise, preoperative biliary drainage is not routinely recommended, as it can be associated with increased morbidity when compared to no preoperative drainage ${ }^{(122)}$. For preoperative drainage, both percutaneous transhepatic biliary drainage (PTBD)

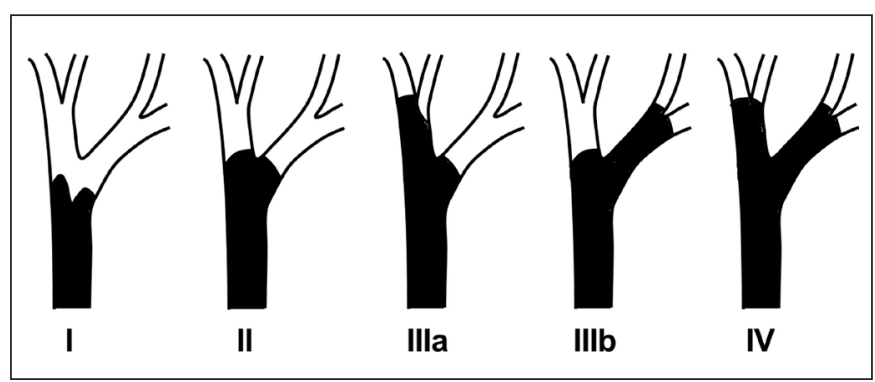

FIGURE 5. The Bismuth-Corlette classification system for biliary strictures. 
and endoscopic biliary drainage (EBD) are suitable options, even though PTBD appears to be associated with a better safety profile and should be recommended as the preferred intervention for patients with CCC types IIIa, IIIb and IV ${ }^{(123,124)}$. Local expertise should also be considered when deciding the appropriate treatment for patients with malignant hilar strictures. In case of cholangitis, preoperative drainage using PTBD approach should be performed with an internal-external biliary stent or with an external catheter (DawsonMueller Drainage Catheter). If EBD is performed, the preference is for the use of plastic stents for preoperative drainage ${ }^{(124)}$.

In the case of advanced unresectable hilar malignancies, palliation with PTBD seems to be superior to $\mathrm{EBD}^{(125)}$. In cases with tumors classified as CCC types I or II, EBD can be performed with good results ${ }^{(126,127)}$. However, endoscopic approach of CCC types IIIa, IIIb or IV is very challenging and superior results with less infectious complications can be obtained with PTBD $^{(124,125)}$. Drainage of more than $50 \%$ of the liver volume was previously related to effective palliation and is considered the optimal goal when treating malignant biliary strictures ${ }^{(106,128,129)}$. However, this goal usually requires bilateral stenting, increasing the complexity of the procedure. More recently, Takahashi et al. showed that a liver volume drainage $\geq 33 \%$ in patients with preserved liver function and $\geq 50 \%$ in patients with impaired liver function correlates with effective biliary drainage in malignant hilar obstruction ${ }^{(130)}$. Similarly to distal malignant obstruction, drainage of unresectable hilar tumors should be performed preferably with SEMS, as these stents are associated with prolonged patency. However, for patients with shorter life expectancy ( $<3$ months), plastic stents would achieve the same benefit of palliation with lower costs (FIGURE 6) ${ }^{(106,124)}$.
In selected cases, combined endoscopic and percutaneous approach ("rendezvous" technique) can be used to treat difficult cases of both distal and hilar malignant obstructions. Endoscopic ultrasonography-guided biliary drainage (EUS-BD) is also an option in cases of ERCP failures with similar success and adverse events rates as compared to percutaneous route ${ }^{(131)}$. The decision to perform EUS-BD will rely on availability and local expertise, preferably after discussion with a multidisciplinary team.

\section{Recommendations}

a) Endoscopic or percutaneous stenting are not routinely recommended for patients with distal or hilar malignant biliary obstruction that are candidates for curative surgery (Class III). In these patients, endoscopic or percutaneous stenting should be restricted to subjects with bacterial cholangitis (Class I), those considered for solely for neoadjuvant therapy or in cases of delayed surgery ( $>3$ weeks) (Class IIb).

b) Biliary stenting by ERCP is recommended for patients with distal malignant biliary obstruction with locally advanced disease who will not be candidates for curative treatments (Class I). PTBD can be recommended in cases where ERCP fails or cannot be performed (Class IIa). PTBD can also be considered in selected centers with high expertise in percutaneous interventions (Class IIb).

c) Plastic stents are recommended for patients with distal malignant biliary obstruction, who are candidates for surgical resection or for those with advanced disease with life expectancy lower than four months (Class I). If surgical resection is uncertain or in cases of neoadjuvant therapy, plastic as well

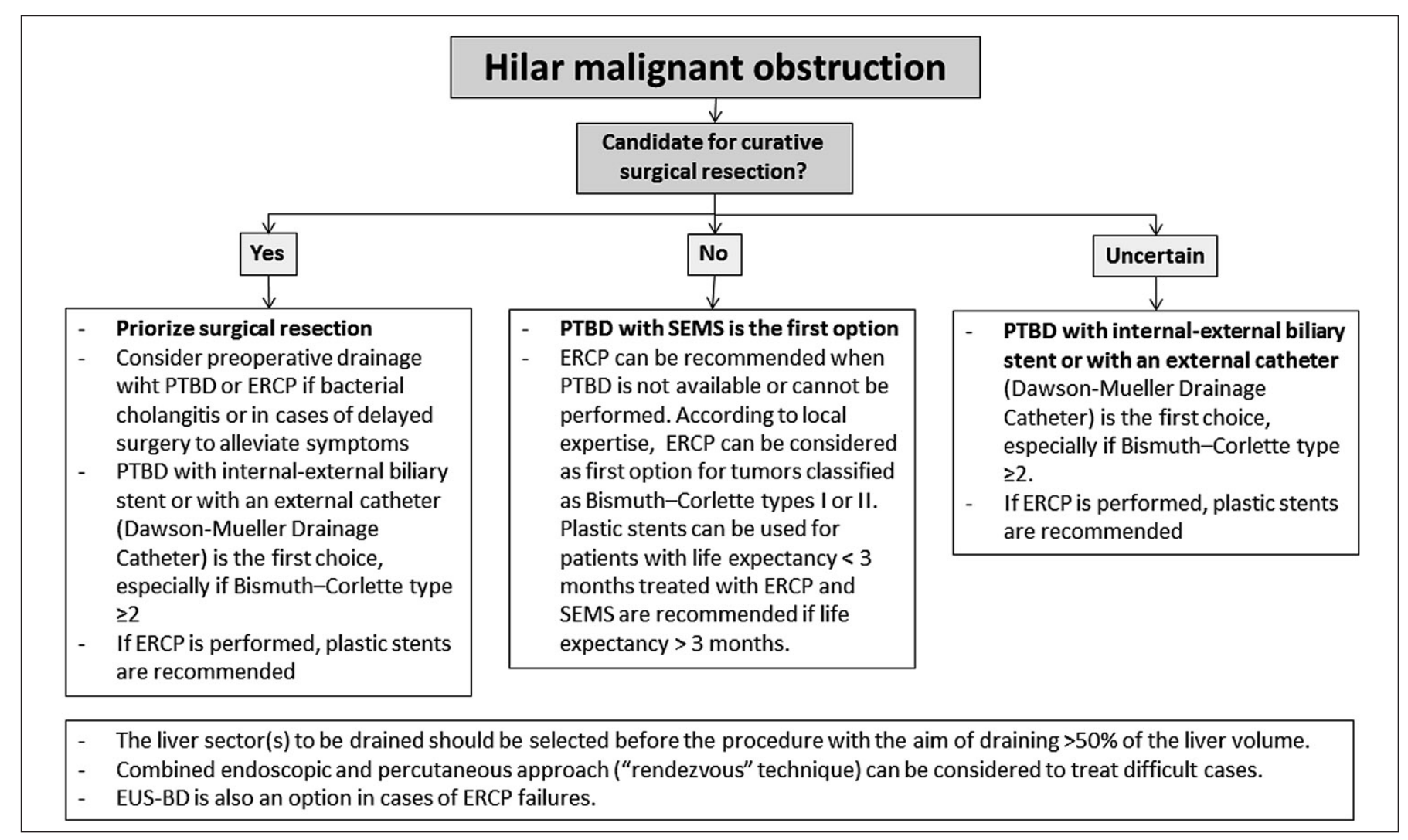

FIGURE 6. Suggested approach to hilar malignant obstruction. 
as short intrapancreatic or covered SEMS may be used, with a preference for covered SEMS in patients who are candidates for neoadjuvant therapies (Class IIb). SEMS are recommended for patients with longer life expectancy ( $>4$ months) who are not candidates for surgical resection (Class I).

d) PTBD is recommended for patients with malignant hilar obstruction with locally advanced disease who will not be candidates for curative treatments (Class I). ERCP can be recommended for patients with malignant hilar obstruction with tumors classified as CCC types I or II (Class IIa) and may be also considered for CCC types IIIa, IIIb or IV when PTBD is not available or cannot be performed (Class IIb).

e) For patients treated by PTBD with distal or hilar malignant biliary obstruction who are candidates for surgical resection or in cases of uncertainty regarding surgical therapy, use of an internal-external biliary stent or an external catheter (Dawson-Mueller Drainage Catheter) is recommended (Class I). SEMS are recommended for those who are not candidates for surgical resection (Class I).

f) For patients treated by ERCP, plastic stents are recommended in cases of malignant hilar obstruction in candidates for surgical resection (Class I) and can be used in those with advanced disease with life expectancy lower than 3 months (Class IIa). SEMS are recommended for patients with longer life expectancy who are not candidates for surgical resection (Class I).

g) In malignant hilar obstruction, the liver sector(s) to be drained should be selected before the procedure with the aim of draining $>50 \%$ of the liver volume (Class IIa).

h) Combined endoscopic and percutaneous approach ("rendez- vous" technique) can be considered to treat difficult cases of both distal and hilar malignant obstructions (Class IIb).

i) EUS-BD is also an option in cases of ERCP failures and the decision to perform EUS-BD will rely on availability and local expertise (Class IIb).

\section{Benign biliary stricture}

Benign biliary strictures are usually a postoperative complication, more frequently occurring after cholecystectomy, LT or other invasive procedures involving the biliary tract. Inflammatory disorders such as chronic pancreatitis and PSC can also be associated with biliary strictures. Although diagnosis is outside the scope of this paper, patients with suspected benign biliary stricture should be adequately investigated in order to select the proper therapeutic intervention. Multidisciplinary collaboration is usually necessary to define the best approach.

Post LT biliary complications are observed in 5\% to $32 \%$ of patients and are more common after living-donor $\mathrm{LT}^{(132-134)}$. Anastomotic biliary strictures are the most frequent complications, and are usually short and isolated, resulting from fibrotic scarring during the first year of $\mathrm{LT}^{(132)}$. Non-anastomotic strictures are observed less frequently and are usually long and can be located in the intrahepatic biliary tract or in the donor duct, proximal to the anastomosis ${ }^{(132-135)}$. Etiologic factors of non-anastomotic strictures can be divided in two categories: (1) ischemic injury (with or without hepatic artery thrombosis), and (2) immune-mediated injury ${ }^{(133-136)}$. Diagnosis of post liver transplant biliary strictures can be challenging and, therefore, an algorithm of a suggested approach to LT patients with elevated liver enzymes and/ or biliary symptoms is presented in FIGURE 7.

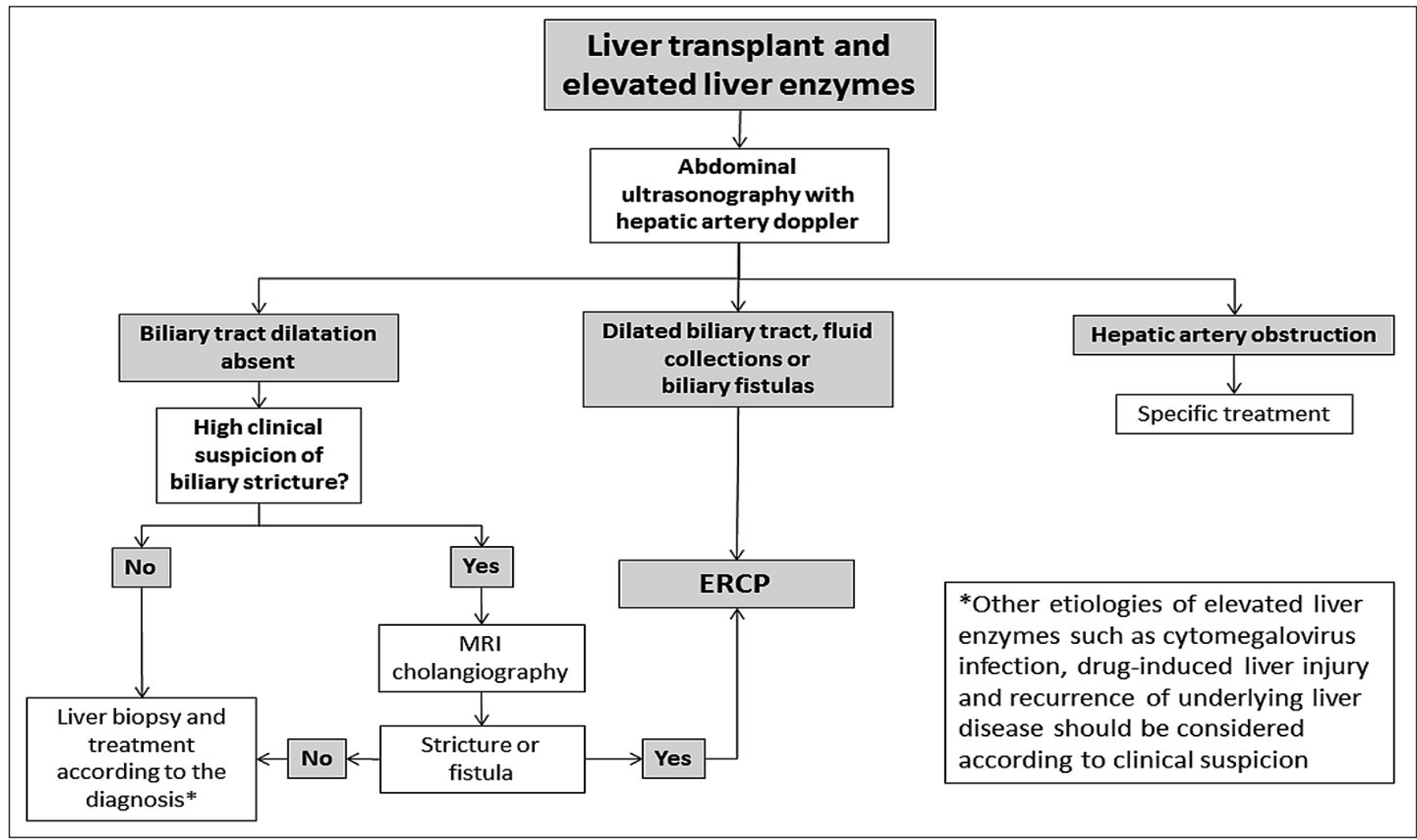

FIGURE 7. Suggested approach to liver transplant patients with elevated liver enzymes and/or biliary symptoms. 
Another frequent cause of biliary obstruction is chronic pancreatitis, in which this complication is observed in up to $46 \%$ of patients ${ }^{(137)}$. The majority of subjects are asymptomatic, although prolonged cholestasis, bacterial cholangitis and progression to secondary biliary cirrhosis can be observed ${ }^{(138,139)}$. The diagnosis requires advanced imaging modalities, such as computerized tomography and/or magnetic resonance cholangiopancreatography. EUS has good sensitivity and specificity and can also be used for diagnosis and therapeutic planning in cases of suspected biliary complications of chronic pancreatitis. Biliary drainage is recommended in cases of symptomatic and/or persistent biliary obstruction.

Benign biliary strictures are usually approached endoscopically and the percutaneous route is reserved for cases of failure of ERCP or for patients with previous Roux-en-Y hepaticojejunostomy. Surgery can be performed for cases of failure of endoscopic and other invasive procedures. Endoscopic approaches include dilation and placement of plastic or metal stents. Benign biliary strictures may be dilated with hydrostatic balloons or graduated catheters passed over a guidewire. Endoscopic dilation followed by stenting is the recommended approach, with resolution rates above $80 \%{ }^{(140-144)}$. Dilation alone is associated with higher recurrence rates and is not routinely recommended ${ }^{(145,146)}$. An aggressive strategy that includes maximum balloon dilation associated with placement of multiple plastic stents is widely used ${ }^{(141,144,147-151)}$. ERCP should be repeated every three or four months during one year period and in every procedure, all stents should be removed and another balloon dilation should be performed, followed again by the placement of multiple stents with progressive increment in the diameter ${ }^{(141,144,147-151)}$.

The major disadvantage of this approach is that it requires multiple ERCP procedures. For this reason, fully covered SEMS are attractive options of benign biliary strictures management. Biliary stenting with covered SEMS has led to stricture resolution rates of $61 \%$ to $100 \%$, with a lower number of procedures, shorter duration of treatment and lower total cost ${ }^{(147-149,151-156)}$. Stent migration rates can be higher than $20 \%$ and is the most important complication of covered SEMS. Migration is associated with therapeutic failure and stricture recurrence that occurs in up to $30 \%$ of the patients $^{(147-149,151,153-158)}$. SEMS are not recommended in cases of hilar or intra-hepatic benign strictures.

Specifically for cases of non-anastomotic post liver transplant biliary strictures, dilation of all strictures is not always possible, depending on the severity, location and multifocal distribution. Serial placement of multiple plastic stents as described above is recommended, even though success rates are usually lower than $75 \%$ with high recurrence rates ${ }^{(159,160)}$.

Recurrence rates after endoscopic treatment of benign biliary strictures are up to $20 \%$ with plastic stents and up to $30 \%$ with covered SEMS. Factors associated with recurrence include late presentation ( $>6$ months after liver transplant), severe stricture, biliary fistula, and need for high volume of blood transfusion in the intraoperative period ${ }^{(134,149,161)}$. TABLE 1 compares multiple plastic stents strategy and covered SEMS in the treatment of benign biliary strictures. Overall, the duration of treatment and number of procedures was inferior with the covered SEMS, with similar success and complication rates, but with higher recurrence rates in SEMS group ${ }^{(149)}$.

PTBD is recommended for cases of severe duct to duct anastomosis strictures and failure in retrograde access for a combined approach attempt ("rendezvous" technique). PTBD is also considered
TABLE 1. Comparison of multiple plastic stents strategy and covered SEMS in the treatment of benign biliary strictures.

\begin{tabular}{lcc}
\hline & $\begin{array}{c}\text { Multiple } \\
\text { plastic stents }\end{array}$ & $\begin{array}{c}\text { Covered } \\
\text { SEMS }\end{array}$ \\
\hline $\begin{array}{l}\text { Duration of treatment } \\
\text { Number of procedures }\end{array}$ & $4-5$ months & \pm 6 months \\
Success rate according the type of stricture & 2 \\
Postcholecystectomy & $87 \%-100 \%$ & $62 \%-100 \%$ \\
Anastomotic & $82 \%-98 \%$ & $87 \%-100 \%$ \\
Non-anastomotic & $50 \%-75 \%$ & NA \\
Chronic pancreatitis & $66 \%-90 \%$ & $79 \%-84 \%$ \\
Complication rate & $4 \%-16 \%$ & $4 \%-18 \%$ \\
Stent migration & $5 \%-33 \%$ & $4 \%-47 \%$ \\
Recurrence & $0-20 \%$ & $5 \%-32 \%$ \\
Cost & US\$16,095 & US\$6,903 \\
\hline SEMS: self-expandable metallic stent. & &
\end{tabular}

the modality of choice for patients with surgically altered anatomy. The treatment consists of a balloon dilation of the stricture (4 to $10 \mathrm{~mm}$ ) followed by the insertion of an internal-external biliary stent $(8.5$ to $12 \mathrm{~F})$. Elective catheter exchange should be performed on average every three weeks, for at least three months. Success rates of this approach range to $40 \%$ to $89.5 \%$ with an average $12 \%$ relapse rate. External biliary drainage is associated with significant morbidity and impairment in quality of life, with complication rates around $21 \%$, including bleeding and bile leakage ${ }^{(162-164)}$.

A meta-analysis was published in 2017 including 27 studies addressing endoscopic, percutaneous and surgical approaches for benign biliary strictures ${ }^{(165)}$. Significant heterogeneity was observed regarding therapeutic protocols, types of stents, previous interventions, and endpoints definition. Overall, stricture resolution was described in $80 \%$ to $94 \%$ of the cases and the authors suggested that endoscopic approach should be prioritized given its safety profile, ease of implementation, and cost-effectiveness for cholecystectomy and liver transplant-related strictures ${ }^{(165)}$. On the other hand, patients with strictures related to chronic pancreatitis can be initially considered for surgical therapy given the better long-term results with this approach ${ }^{(165)}$. To date, PTBD has been being recommended as the "standard of care" for patients with biliary obstruction when ERCP failed. More recently, EUS-BD has emerged as a suitable option for those patients. Although data on EUS-BD still very limited, especially for benign diseases, some series suggest that this approach has a high success rate as a rescue therapy for cases of ERCP failure and also as initial approach ${ }^{(166-168)}$. Direct cholangioscopy (spyglass) is currently available in some centers as an interesting option that allows the direct visualization of the stricture facilitatating its transposition in severe cases. Even though the device presents a high cost, an analysis performed in a Brazilian institution showed that this technique presented a cost lower than EUS-BD and PTBD ${ }^{(169)}$. However, data on the use of EUS-BD and direct cholangioscopy in cases of benign biliary strictures still very limited and these procedures should be considered only in selected centers with high expertise and when PTBD is not available or cannot be performed. 


\section{Recommendations}

a) Endoscopic therapy with balloon dilation and placement of multiple plastic stents is the first-line approach for benign biliary strictures. (Class I)

b) Fully covered SEMS could be considered as an alternative approach for anastomotic strictures as this strategy has been associated with lower number of procedures and reduced global cost of therapy (Class IIb). However, covered SEMS are associated with higher migration rates and more studies are needed to clarify the ideal length of time the stent should remain in place.

c) PTBD is recommended in cases of failure or unavailability of ERCP, or when ERCP is not feasible, usually due to surgically altered anatomy (Class I).

d) EUS-BD and direct cholangioscopy could be considered for selected cases of benign biliary strictures in highly specialized centers (Class IIb). More data is necessary before such modalities can be widely recommended.

\section{Dominant strictures in PSC}

PSC is an autoimmune chronic cholestatic disease characterized by inflammation, fibrosis and strictures of intra- or extrahepatic bile ducts. Details about diagnostic approaches and treatment of patients with PSC are outside the scope of this paper and are outlined elsewhere ${ }^{(170)}$. Dominant stricture (DS) is defined as a stenosis $\leq 1.5 \mathrm{~mm}$ in diameter in the common bile duct and/or $\leq 1.0 \mathrm{~mm}$ in the hepatic duct ${ }^{(171)}$. DS are present in almost half of patients at initial presentation of PSC. Up to $60 \%$ of the subjects will develop at least one DS during the course of the disease ${ }^{(172,173)}$. Abdominal ultrasound and computerized tomography are of little value in patients with clinically suspected DS. MR cholangiography has sensitivity and specificity comparable to ERCP and, therefore, should be considered the modality of choice for diagnosis and therapeutic planning of $\mathrm{DS}^{(174-176)}$.

The therapeutic approach to DS can be endoscopic, percutaneous or surgical. DS are usually amenable to endoscopic treatment. Even so, therapeutic intervention should be reserved for symptomatic patients since there is no evidence of benefit for treatment of asymptomatic subjects ${ }^{(171,176,177)}$. Prophylactic antibiotics are recommended for prevention of post-procedure bacterial cholangitis in patients with PSC who undergo ERCP(171,176,177). Treatment of DS should be performed either by balloon or passage dilators ${ }^{(171,176,177)}$. Stent placement after dilation is not routinely recommended as it can increase the risk of bacterial cholangitis. On the other hand, stenting can be necessary in cases of severe strictures and, in those patients, stents should be kept for a short period of time (176,178,179). $^{2}$ Bile duct stones, if present, should always be removed and if located above a stricture, this should be dilated before the removal of the stones. Endoscopic therapy has been associated with radiological, laboratory, and clinical improvement in patients with PSC. In addition, endoscopic therapy of DS in PSC seems to improve prognosis and increase survival ${ }^{(171,180)}$.

Percutaneous approach should be reserved for patients with ERCP failure or unavailability, or when the procedure is not feasible due to surgically altered anatomy ${ }^{(176,181,182)}$. Complication rate is slightly higher with the percutaneous treatment, including local pain, hepatic artery injury, hemobilia and cholangitis ${ }^{(17,6181,182)}$.

Surgical therapy of DS, including hepaticojejunostomy, increases significantly the risk of recurrent bacterial cholangitis and might hamper access for eventual LT. Therefore, over the last years, a surgical approach has been largely replaced for nonsurgical options in the treatment of $\operatorname{PSC}^{(176,183)}$.

Incidence of CCC is significantly high in patients with PSC and it should be suspected in every subject with rapid clinical deterioration, jaundice and weight loss. CCC should also be considered in all PSC patients with a DS, especially in the presence of progressive biliary dilatation or thickening of bile duct wall ${ }^{(184,185)}$. Almost half of the cases of CCC are detected in the first year of the diagnosis of PSC ${ }^{(184,185)}$.

In cases of suspected CCC, tumor markers, such as carbohydrate antigen 19-9 (CA 19-9) and carcinoembryonic antigen (CEA), should be measured. Alpha-fetoprotein (AFP) is also recommended in cases of intrahepatic tumors. The imaging modality of choice in these cases is magnetic resonance cholangiopancreatography (MRCP) and if the diagnosis is not defined by the combination of imaging and tumor markers, the patient should be referred for ERCP. During ERCP, brush cytology coupled with fluorescence in situ hybridization (FISH) and biopsies should be performed in all intraductal strictures to rule out $\mathrm{CCC}^{(185)}$. FISH can increase the sensitivity of cytologic samples evaluation from $30 \%-40 \%$ to $64 \%{ }^{(186)}$.

Direct cholangioscopy can be considered, if available, as it allows direct visualization of bile duct and can guide biopsies of suspected areas, increasing sensitivity and specificity to values above $90 \%{ }^{(187)}$. Confocal laser microscopy has sensitivity of $98 \%$ with $67 \%$ specificity for indeterminate strictures and can be performed, even though it was not studied specifically in patients with PSC ${ }^{(188)}$. If the lesion cannot be endoscopically assessed, percutaneous approach can be considered.

If cholangiocarcinoma is strongly suspected but the diagnosis can not established by ERCP, the combination of positron emission tomography (PET) with computed tomography (PET-CT) can be useful to identify areas with high probability of malignancy prior to surgical approach ${ }^{(189)}$. If the diagnosis is still uncertain after this approach, a close follow-up is recommended with new imaging and laboratory evaluation after three months.

\section{Recommendations}

a) MR cholangiography has sensitivity and specificity comparable to ERCP and, therefore, should be recommended as the modality of choice for diagnosis and therapeutic planning of DS in patients with PSC (Class I).

b) ERCP with balloon dilatation is the recommended approach in symptomatic patients with PSC and DS (Class I). Stent placement after dilation is not routinely recommended as it can increase the risk of bacterial cholangitis (Class III). Stenting can be necessary for a short period of time in cases of severe strictures (Class IIa). Ductal sampling (brush cytology and/or endobiliary biopsies) during ERCP is recommended for all patients with PSC and DS to rule out CCC (Class I).

c) Prophylactic antibiotics are recommended for prevention of post-procedure bacterial cholangitis in patients with PSC who undergo ERCP (Class I).

d) Percutaneous approach to treat DS in PSC should be reserved for cases of failure of ERCP, or when ERCP is not feasible, usually due to surgically altered anatomy (Class IIa).

e) CCC should be suspected in patients with PSC and worsening cholestasis, new or progressive dominant stricture, weight loss and elevated serum CA19-9 (Class I). ERCP 
with ductal sampling (brush cytology and/or endobiliary biopsies) is recommended in cases of suspected CCC (Class I). FISH can increase the sensitivity of cytologic samples and should be performed if available (Class I). Direct cholangioscopy and confocal laser microscopy can be recommended for the diagnosis of cholangiocarcinoma in PSC, if available (Class IIa).

\section{Orcid}

Leonardo de Lucca Schiavon. Orcid: 0000-0003-4340-6820.

Flávio Hayato Ejima. Orcid: 0000-0002-5925-0958.

Marcos Roberto de Menezes. Orcid: 0000-0001-7231-2925.

Paulo Lisboa Bittencourt. Orcid: 0000-0003-0883-4870.

Aírton Mota Moreira. Orcid: 0000-0002-0649-2208.

Alberto Queiroz Farias. Orcid: 0000-0002-5572-663x.

Aline Lopes Chagas. Orcid: 0000-0002-7404-2540.

André Moreira de Assis. Orcid: 0000-0001-8924-7680.

Ângelo Zambam de Mattos. Orcid: 0000-0002-3063-0199.

Bruno Chaves Salomão. Orcid: 0000-0003-1882-8642.
Carlos Terra. Orcid: 0000-0003-3069-128X.

Fernanda Prata Borges Martins. Orcid: 0000-0002-7017-9910.

Francisco Cesar Carnevale. Orcid: 0000-0003-2659-9624.

Guilherme Ferreira da Motta Rezende. Orcid: 0000-00032235-2296.

Gustavo Andrade de Paulo. Orcid: 0000-0002-7926-9373.

Gustavo Henrique Santos Pereira. Orcid: 0000-0003-2768-9605. Joaquim Maurício da Motta Leal Filho. Orcid: 0000-00019844-6833.

Juliana de Meneses. Orcid: 0000-0001-6159-9991.

Lucas Santana Nova da Costa. Orcid: 0000-0003-0422-1540.

Marcos de Vasconcelos Carneiro. Orcid: 0000-0003-4151-0114.

Mário Reis Álvares-da-Silva. Orcid: 0000-0002-5001-246X.

Mayra Veloso Ayrimoraes Soares. Orcid: 0000-0003-0796-5123.

Osvaldo Ignácio Pereira. Orcid: 0000-0002-4238-6023.

Rafael Oliveira Ximenes. Orcid: 0000-0001-8689-7987.

Renata Filardi Simiqueli Durante. Orcid: 0000-0003-0826-3203.

Valério Alves Ferreira. Orcid: 0000-0002-6819-672X.

Vinícius Machado de Lima. Orcid: 0000-0002-6068-9503.

Schiavon LL, Ejima FH, Menezes MR, Bittencourt PL, and Members of the Pannel of the 1st Joint Meeting of the SBH, SOBED and SOBRICE. Recomendações sobre procedimentos invasivos em pacientes com doenças do fígado e do trato biliar: relatório de reunião conjunta da Sociedade Brasileira de Hepatologia (SBH), Sociedade Brasileira de Endoscopia Digestiva (SOBED) e Sociedade Brasileira de Radiologia Intervencionista e Cirurgia Endovascular (SOBRICE). Arq Gastroenterol. 2019;56(2):213-31.

RESUMO - As doenças do fígado e das vias biliares são causas comuns de morbidade e mortalidade. Procedimentos invasivos com finalidade diagnóstica e terapêutica são frequentemente recomendados nos casos de doenças hepatobiliares. O reconhecimento das indicações e limitações das técnicas comumente empregadas é crucial para uma adequada seleção dos pacientes, maximizando os resultados positivos e reduzindo o risco de complicações. Em 2018, a Sociedade Brasileira de Hepatologia (SBH), em colaboração com a Sociedade Brasileira de Radiologia Intervencionista e Cirurgia Endovascular (SOBRICE) e a Sociedade Brasileira de Endoscopia Digestiva (SOBED) realizaram um encontro exclusivamente voltado para a discussão dos procedimentos invasivos nas doenças hepatobiliares. Este texto resume as principais recomendações discutidas durante o evento, e tem a intenção de auxiliar clínicos, gastroenterologistas, hepatologistas, radiologistas e endoscopistas no uso adequado dos procedimentos invasivos para manejo de pacientes com doenças hepatobiliares.

DESCRITORES - Procedimentos cirúrgicos minimamente invasivos. Hipertensão portal. Carcinoma hepatocelular. Doenças biliares.

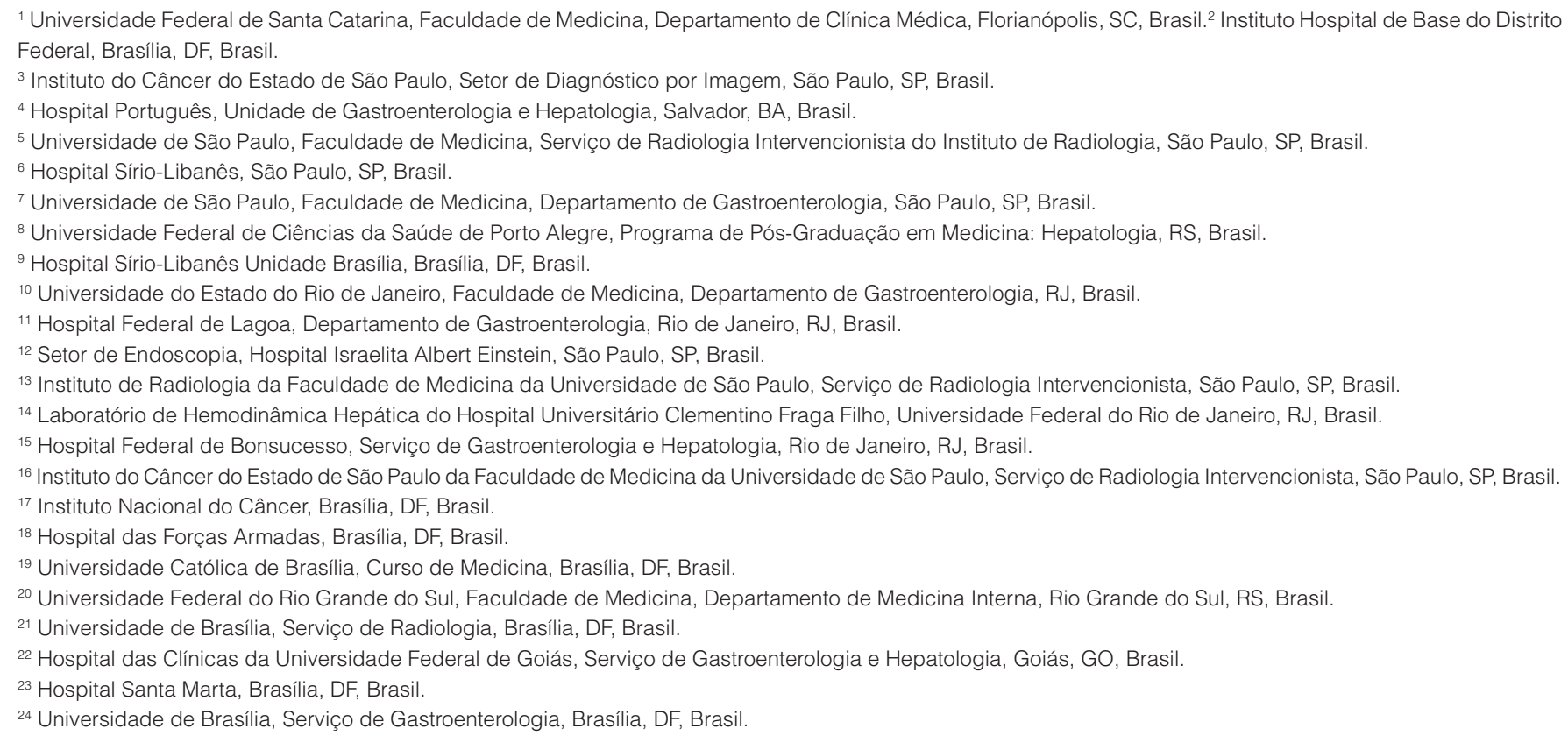




\section{REFERENCES}

1. Rowe IA. Lessons from Epidemiology: The Burden of Liver Disease. Dig Dis 2017;35:304-9.

2. Pimpin L, Cortez-Pinto H, Negro F, Corbould E, Lazarus JV, Webber L, et al Burden of liver disease in Europe: Epidemiology and analysis of risk factors to identify prevention policies. J Hepatol. 2018;69:718-35.

3. Byass P. The global burden of liver disease: a challenge for methods and for public health. BMC Med. 2014;12:159.

4. Boonstra K, Beuers U, Ponsioen CY. Epidemiology of primary sclerosing cholangitis and primary biliary cirrhosis: a systematic review. J Hepatol. 2012;56:1181-8.

5. Bergquist A, von Seth E. Epidemiology of cholangiocarcinoma. Best Pract Res Clin Gastroenterol. 2015;29:221-32.

6. Committees MMfAAGW. Methodology Manual and Policies From the ACCF/ AHA Task Force on Practice Guidelines. June 2010.

7. Moore KP, Wong F, Gines P, Bernardi M, Ochs A, Salerno F, et al. The management of ascites in cirrhosis: report on the consensus conference of the International Ascites Club. Hepatology. 2003;38:258-66

8. Caly WR, Abreu RM, Bitelman B, Carrilho FJ, Ono SK. Clinical Features of Refractory Ascites in Outpatients. Clinics. 2017;72:405-10.

9. Salerno F, Guevara M, Bernardi M, Moreau R, Wong F, Angeli P, et al. Refractory ascites: pathogenesis, definition and therapy of a severe complication in patients with cirrhosis. Liver Int. 2010;30:937-47.

10. Moreau R, Delegue P, Pessione F, Hillaire S, Durand F, Lebrec D, et al. Clinical characteristics and outcome of patients with cirrhosis and refractory ascites Liver Int. 2004;24:457-64

11. Adebayo D, Neong SF, Wong F. Refractory Ascites in Liver Cirrhosis. Am J Gastroenterol. 2018

12. Lebrec D, Giuily N, Hadengue A, Vilgrain V, Moreau R, Poynard T, et al Transjugular intrahepatic portosystemic shunts: comparison with paracentesis in patients with cirrhosis and refractory ascites: a randomized trial. French Group of Clinicians and a Group of Biologists. J Hepatol. 1996;25:135-44.

13. Rossle M, Ochs A, Gulberg V, Siegerstetter V, Holl J, Deibert P, et al. A comparison of paracentesis and transjugular intrahepatic portosystemic shunting in patients with ascites. N Engl J Med. 2000;342:1701-7.

14. Gines P, Uriz J, Calahorra B, Garcia-Tsao G, Kamath PS, Del Arbol LR, et al. Transjugular intrahepatic portosystemic shunting versus paracentesis plus albumin for refractory ascites in cirrhosis. Gastroenterology. 2002;123:1839-47.

15. Salerno F, Merli M, Riggio O, Cazzaniga M, Valeriano V, Pozzi M, et al. Randomized controlled study of TIPS versus paracentesis plus albumin in cirrhosis with severe ascites. Hepatology. 2004;40:629-35.

16. Sanyal AJ, Genning C, Reddy KR, Wong F, Kowdley KV, Benner K, et al. The North American Study for the Treatment of Refractory Ascites. Gastroenterology. 2003;124:634-41.

17. Narahara Y, Kanazawa H, Fukuda T, Matsushita Y, Harimoto H, Kidokoro $\mathrm{H}$, et al. Transjugular intrahepatic portosystemic shunt versus paracentesis plus albumin in patients with refractory ascites who have good hepatic and renal function: a prospective randomized trial. J Gastroenterol. 2011;46:78-85.

18. Bureau C, Thabut D, Oberti F, Dharancy S, Carbonell N, Bouvier A, et al Transjugular Intrahepatic Portosystemic Shunts With Covered Stents Increase Transplant-Free Survival of Patients With Cirrhosis and Recurrent Ascites. Gastroenterology. 2017;152:157-63.

19. Salerno F, Camma C, Enea M, Rossle M, Wong F. Transjugular intrahepatic portosystemic shunt for refractory ascites: a meta-analysis of individual patient data. Gastroenterology. 2007;133:825-34

20. Bai M, Qi XS, Yang ZP, Yang M, Fan DM, Han GH. TIPS improves liver transplantation-free survival in cirrhotic patients with refractory ascites: an updated meta-analysis. World J Gastroenterol. 2014;20:2704-14.

21. Gines A, Escorsell A, Gines P, Salo J, Jimenez W, Inglada L, et al. Incidence, predictive factors, and prognosis of the hepatorenal syndrome in cirrhosis with ascites. Gastroenterology. 1993;105:229-36

22. Schrier RW, Arroyo V, Bernardi M, Epstein M, Henriksen JH, Rodes J. Periphera arterial vasodilation hypothesis: a proposal for the initiation of renal sodium and water retention in cirrhosis. Hepatology. 1988;8:1151-7.

23. Arroyo V, Terra C, Gines P. Advances in the pathogenesis and treatment of type-1 and type-2 hepatorenal syndrome. J Hepatol. 2007:46:935-46.

24. Arroyo V, Gines P, Gerbes AL, Dudley FJ, Gentilini P, Laffi G, et al. Definition and diagnostic criteria of refractory ascites and hepatorenal syndrome in cirrhosis. International Ascites Club. Hepatology. 1996;23:164-76.

25. Angeli P, Gines P, Wong F, Bernardi M, Boyer TD, Gerbes A, et al. Diagnosis and management of acute kidney injury in patients with cirrhosis: revised consensus recommendations of the International Club of Ascites. J Hepatol. 2015;62:968-74.

26. European Association for the Study of the Liver. Electronic address eee, European Association for the Study of the L. EASL Clinical Practice Guidelines for the management of patients with decompensated cirrhosis. J Hepatol. 2018;69:406-60.
27. Terra C, Mattos AZ, Pereira G, Farias AQ, Kondo M, Mattos AA, et al. Recommendations of the Brazilian Society of Hepatology for the Management of Acute Kidney Injury in Patients with Cirrhosis. Arq Gastroenterol. 2018;55:314-20.

28. Brensing KA, Textor J, Perz J, Schiedermaier P, Raab P, Strunk H, et al. Long term outcome after transjugular intrahepatic portosystemic stent-shunt in non-transplant cirrhotics with hepatorenal syndrome: a phase II study. Gut. 2000;47:288-95.

29. Guevara M, Gines P, Bandi JC, Gilabert R, Sort P, Jimenez W, et al. Transjugular intrahepatic portosystemic shunt in hepatorenal syndrome: effects on renal function and vasoactive systems. Hepatology. 1998;28:416-22.

30. Wong F, Pantea L, Sniderman K. Midodrine, octreotide, albumin, and TIPS in selected patients with cirrhosis and type 1 hepatorenal syndrome. Hepatology. 2004:40:55-64.

31. Testino G, Leone S, Ferro C, Borro P. Severe acute alcoholic hepatitis and hepatorenal syndrome: role of transjugular intrahepatic portosystemic stent shunt. J Med Life. 2012;5:203-5.

32. Song T, Rossle M, He F, Liu F, Guo X, Qi X. Transjugular intrahepatic portosystemic shunt for hepatorenal syndrome: A systematic review and meta-analysis. Dig Liver Dis. 2018;50:323-30

33. Bittencourt PL, Strauss E, Farias AQ, Mattos AA, Lopes EP. Variceal Bleeding: Update of Recommendations from the Brazilian Association of Hepatology. Arq Gastroenterol. 2017;54:349-55

34. Sharma M, Singh S, Desai V, Shah VH, Kamath PS, Murad MH, et al. Comparison of Therapies for Primary Prevention of Esophageal Variceal Bleeding. A Systematic Review and Network Meta-analysis. Hepatology. 2019;69:1657-75.

35. Tripathi D, Ferguson JW, Kochar N, Leithead JA, Therapondos G, McAvoy NC, et al. Randomized controlled trial of carvedilol versus variceal band ligation for the prevention of the first variceal bleed. Hepatology. 2009;50:825-33.

36. Shah HA, Azam Z, Rauf J, Abid S, Hamid S, Jafri W, et al. Carvedilol vs. esophageal variceal band ligation in the primary prophylaxis of variceal hemorrhage: a multicentre randomized controlled trial. J Hepatol. 2014;60:757-64.

37. van Buuren HR, Rasch MC, Batenburg PL, Bolwerk CJ, Nicolai JJ, van der Werf $\mathrm{SD}$, et al. Endoscopic sclerotherapy compared with no specific treatment for the primary prevention of bleeding from esophageal varices. A randomized controlled multicentre trial [ISRCTN03215899]. BMC gastroenterology. 2003;3:22.

38. Avgerinos A, Armonis A, Manolakopoulos S, Rekoumis G, Argirakis G, Viazis $\mathrm{N}$, et al. Endoscopic sclerotherapy plus propranolol versus propranolol alone in the primary prevention of bleeding in high risk cirrhotic patients with esophageal varices: a prospective multicenter randomized trial. Gastrointest Endosc. 2000;51:652-8

39. Duhamel O, Carle JP, Daures JP, Boyer A, Gislon J, Nalet B, et al. [Primary prevention of digestive hemorrhage, caused by rupture of esophageal varices, by endoscopic sclerotherapy in patients with liver cirrhosis. Multicenter randomized controlled study]. Gastroenterol Clin Biol. 1994;18:57-62.

40. Sarin SK, Lahoti D, Saxena SP, Murthy NS, Makwana UK. Prevalence, classification and natural history of gastric varices: a long-term follow-up study in 568 portal hypertension patients. Hepatology. 1992;16:1343-9.

41. de Franchis R, Baveno VIF. Expanding consensus in portal hypertension: Report of the Baveno VI Consensus Workshop: Stratifying risk and individualizing care for portal hypertension. J Hepatol. 2015;63:743-52.

42. Mishra SR, Sharma BC, Kumar A, Sarin SK. Primary prophylaxis of gastric variceal bleeding comparing cyanoacrylate injection and beta-blockers: a randomized controlled trial. J Hepatol. 2011;54:1161-7.

43. Haq I, Tripathi D. Recent advances in the management of variceal bleeding Gastroenterology report. 2017;5:113-26.

44. Banares R, Albillos A, Rincon D, Alonso S, Gonzalez M, Ruiz-del-Arbol L, et al. Endoscopic treatment versus endoscopic plus pharmacologic treatment for acute variceal bleeding: a meta-analysis. Hepatology. 2002;35:609-15.

45. Lo GH, Chen WC, Wang HM, Lin CK, Chan HH, Tsai WL, et al. Low-dose terlipressin plus banding ligation versus low-dose terlipressin alone in the prevention of very early rebleeding of oesophageal varices. Gut. 2009;58:1275-80.

46. Cardenas A, Baiges A, Hernandez-Gea V, Garcia-Pagan JC. Endoscopic hemostasis in acute esophageal variceal bleeding. Gastroenterology clinics of North America. 2014;43:795-806

47. Abraldes JG, Bosch J. The treatment of acute variceal bleeding. J Clin Gastroenterol. 2007:41 Suppl 3:S312-7.

48. Avgerinos A, Armonis A, Stefanidis G, Mathou N, Vlachogiannakos J, Kougioumtzian A, et al. Sustained rise of portal pressure after sclerotherapy, but no band ligation, in acute variceal bleeding in cirrhosis. Hepatology. 2004;39:1623-30

49. Dai C, Liu WX, Jiang M, Sun MJ. Endoscopic variceal ligation compared with endoscopic injection sclerotherapy for treatment of esophageal variceal hemorrhage: a meta-analysis. World J Gastroenterol. 2015;21:2534-41. 
50. Garcia-Pagan JC, Caca K, Bureau C, Laleman W, Appenrodt B, Luca A, et al. Early use of TIPS in patients with cirrhosis and variceal bleeding. N Engl J Med. 2010;362:2370-9.

51. Garcia-Pagan JC, Di Pascoli M, Caca K, Laleman W, Bureau C, Appenrodt B, et al. Use of early-TIPS for high-risk variceal bleeding: results of a post-RCT surveillance study. J Hepatol. 2013;58:45-50

52. Lo GH, Lai KH, Cheng JS, Chen MH, Chiang HT. A prospective, randomized trial of butyl cyanoacrylate injection versus band ligation in the management of bleeding gastric varices. Hepatology. 2001;33:1060-4

53. Sarin SK, Jain AK, Jain M, Gupta R. A randomized controlled trial of cyanoacrylate versus alcohol injection in patients with isolated fundic varices. Am J Gastroenterol. 2002;97:1010-5.

54. Tan PC, Hou MC, Lin HC, Liu TT, Lee FY, Chang FY, et al. A randomized trial of endoscopic treatment of acute gastric variceal hemorrhage: N-butyl-2-cyanoacrylate injection versus band ligation. Hepatology. 2006;43:690-7.

55. Azoulay D, Castaing D, Majno P, Saliba F, Ichai P, Smail A, et al. Salvage transjugular intrahepatic portosystemic shunt for uncontrolled variceal bleeding in patients with decompensated cirrhosis. J Hepatol. 2001;35:590-7.

56. Vangeli M, Patch D, Burroughs AK. Salvage tips for uncontrolled variceal bleeding. J Hepatol. 2002;37:703-4.

57. Shao XD, Qi XS, Guo XZ. Esophageal Stent for Refractory Variceal Bleeding: A Systemic Review and Meta-Analysis. Biomed Res Int. 2016;2016:4054513.

58. Garcia-Tsao G, Abraldes JG, Berzigotti A, Bosch J. Portal hypertensive bleeding in cirrhosis: Risk stratification, diagnosis, and management: 2016 practice guidance by the American Association for the study of liver diseases. Hepatology. 2017:65:310-35.

59. Puente A, Hernandez-Gea V, Graupera I, Roque M, Colomo A, Poca M, et al. Drugs plus ligation to prevent rebleeding in cirrhosis: an updated systematic review. Liver Int. 2014;34:823-33.

60. Holster IL, Tjwa ET, Moelker A, Wils A, Hansen BE, Vermeijden JR, et al. Covered transjugular intrahepatic portosystemic shunt versus endoscopic therapy + beta-blocker for prevention of variceal rebleeding. Hepatology. 2016;63:581-9.

61. Sauerbruch T, Mengel M, Dollinger M, Zipprich A, Rossle M, Panther E, et al. Prevention of Rebleeding From Esophageal Varices in Patients With Cirrhosis Receiving Small-Diameter Stents Versus Hemodynamically Controlled Medical Therapy. Gastroenterology. 2015;149:660-8 e1

62. Mishra SR, Chander Sharma B, Kumar A, Sarin SK. Endoscopic cyanoacrylate injection versus beta-blocker for secondary prophylaxis of gastric variceal bleed: a randomised controlled trial. Gut. 2010;59:729-35.

63. Hung HH, Chang CJ, Hou MC, Liao WC, Chan CC, Huang HC, et al. Efficacy of non-selective beta-blockers as adjunct to endoscopic prophylactic treatment for gastric variceal bleeding: a randomized controlled trial. J Hepatol. 2012;56: 1025-32.

64. Lo GH, Liang HL, Chen WC, Chen MH, Lai KH, Hsu PI, et al. A prospective, randomized controlled trial of transjugular intrahepatic portosystemic shunt versus cyanoacrylate injection in the prevention of gastric variceal rebleeding. Endoscopy. 2007:39:679-85.

65. Lipnik AJ, Pandhi MB, Khabbaz RC, Gaba RC. Endovascular Treatment for Variceal Hemorrhage: TIPS, BRTO, and Combined Approaches. Semin Intervent Radiol. 2018:35:169-84

66. Wang YB, Zhang JY, Gong JP, Zhang F, Zhao Y. Balloon-occluded retrograde transvenous obliteration versus transjugular intrahepatic portosystemic shun for treatment of gastric varices due to portal hypertension: A meta-analysis. J Gastroenterol Hepatol. 2016;31:727-33.

67. Hall PS, Teshima C, May GR, Mosko JD. Endoscopic Ultrasound-Guided Vascular Therapy: The Present and the Future. Clinical endoscopy. 2017;50:138-42.

68. Ferlay J, Soerjomataram I, Dikshit R, Eser S, Mathers C, Rebelo M, et al. Cancer incidence and mortality worldwide: sources, methods and major patterns in GLOBOCAN 2012. Int J Cancer. 2015;136:E359-86.

69. Sangiovanni A, Prati GM, Fasani P, Ronchi G, Romeo R, Manini M, et al. The natural history of compensated cirrhosis due to hepatitis C virus: A 17-year cohort study of 214 patients. Hepatology. 2006;43:1303-10

70. Alazawi W, Cunningham M, Dearden J, Foster GR. Systematic review: outcome of compensated cirrhosis due to chronic hepatitis C infection. Aliment Pharmacol Ther. 2010;32:344-55.

71. Bruix J, Reig M, Sherman M. Evidence-Based Diagnosis, Staging, and Treatment of Patients With Hepatocellular Carcinoma. Gastroenterology. 2016;150 $835-53$.

72. Carrilho FJ, Mattos AA, Vianey AF, Vezozzo DC, Marinho F, Souto FJ, et al. Brazilian society of hepatology recommendations for the diagnosis and treatment of hepatocellular carcinoma. Arq Gastroenterol. 2015;52 (Suppl 1):2-14.

73. European Association for the Study of the Liver. Electronic address eee, European Association for the Study of the L. EASL Clinical Practice Guidelines: Management of hepatocellular carcinoma. J Hepatol. 2018;69:182-236.
74. Heimbach JK, Kulik LM, Finn RS, Sirlin CB, Abecassis MM, Roberts LR, et al. AASLD guidelines for the treatment of hepatocellular carcinoma. Hepatology. 2018;67:358-80

75. Lencioni R. New data supporting modified RECIST (mRECIST) for Hepatocellular Carcinoma. Clin Cancer Res. 2013;19:1312-4.

76. Lencioni R, Llovet JM. Modified RECIST (mRECIST) assessment for hepatocellular carcinoma. Semin Liver Dis. 2010;30:52-60.

77. McDermott S, Gervais DA. Radiofrequency ablation of liver tumors. Semin Intervent Radiol. 2013;30:49-55.

78. Ansari D, Andersson R. Radiofrequency ablation or percutaneous ethanol injection for the treatment of liver tumors. World J Gastroenterol. 2012;18:1003-8.

79. Germani G, Pleguezuelo M, Gurusamy K, Meyer T, Isgro G, Burroughs AK. Clinical outcomes of radiofrequency ablation, percutaneous alcohol and acetic acid injection for hepatocelullar carcinoma: a meta-analysis. J Hepatol. 2010;52:380-8.

80. Cho YK, Kim JK, Kim MY, Rhim H, Han JK. Systematic review of randomized trials for hepatocellular carcinoma treated with percutaneous ablation therapies. Hepatology. 2009;49:453-9.

81. Orlando A, Leandro G, Olivo M, Andriulli A, Cottone M. Radiofrequency thermal ablation vs. percutaneous ethanol injection for small hepatocellular carcinoma in cirrhosis: meta-analysis of randomized controlled trials. Am J Gastroenterol. 2009; 104:514-24

82. Nault JC, Sutter O, Nahon P, Ganne-Carrie N, Seror O. Percutaneous treatment of hepatocellular carcinoma: State of the art and innovations. J Hepatol. 2017.

83. Gardini AC, Marisi G, Canale M, Foschi FG, Donati G, Ercolani G, et al. Radiofrequency ablation of hepatocellular carcinoma: a meta-analysis of overall survival and recurrence-free survival. Onco Targets Ther. 2018;11:6555-67.

84. Majumdar A, Roccarina D, Thorburn D, Davidson BR, Tsochatzis E, Gurusamy KS. Management of people with early- or very early-stage hepatocellular carcinoma: an attempted network meta-analysis. Cochrane Database Syst Rev. 2017;3:CD011650.

85. Cucchetti A, Piscaglia F, Cescon M, Colecchia A, Ercolani G, Bolondi L, et al. Cost-effectiveness of hepatic resection versus percutaneous radiofrequency ablation for early hepatocellular carcinoma. J Hepatol. 2013;59:300-7.

86. Forner A, Gilabert M, Bruix J, Raoul JL. Treatment of intermediate-stage hepatocellular carcinoma. Nat Rev Clin Oncol. 2014;11:525-35.

87. Melchiorre F, Patella F, Pescatori L, Pesapane F, Fumarola E, Biondetti P, et al. DEB-TACE: a standard review. Future Oncol. 2018.

88. Sacco R, Mismas V, Marceglia S, Romano A, Giacomelli L, Bertini M, et al. Transarterial radioembolization for hepatocellular carcinoma: An update and perspectives. World J Gastroenterol. 2015;21:6518-25.

89. Llovet JM, Bruix J. Systematic review of randomized trials for unresectable hepatocellular carcinoma: Chemoembolization improves survival. Hepatology. 2003;37:429-42

90. Lencioni R, Petruzzi P, Crocetti L. Chemoembolization of hepatocellular carcinoma. Semin Intervent Radiol. 2013;30:3-11.

91. Facciorusso A, Di Maso M, Muscatiello N. Drug-eluting beads versus conventional chemoembolization for the treatment of unresectable hepatocellular carcinoma: A meta-analysis. Dig Liver Dis. 2016;48:571-7.

92. Lammer J, Malagari K, Vogl T, Pilleul F, Denys A, Watkinson A, et al. Prospective randomized study of doxorubicin-eluting-bead embolization in the treatment of hepatocellular carcinoma: results of the PRECISION V study. Cardiovasc Intervent Radiol. 2010;33:41-52.

93. Golfieri R, Giampalma E, Renzulli M, Cioni R, Bargellini I, Bartolozzi C, et al. Randomised controlled trial of doxorubicin-eluting beads vs conventional chemoembolisation for hepatocellular carcinoma. Br J Cancer. 2014:111:255-64.

94. Lee YK, Jung KS, Kim DY, Choi JY, Kim BK, Kim SU, et al. Conventional versus drug-eluting beads chemoembolization for hepatocellular carcinoma: Emphasis on the impact of tumor size. J Gastroenterol Hepatol. 2017:32:487-96.

95. Kulik LM, Carr BI, Mulcahy MF, Lewandowski RJ, Atassi B, Ryu RK, et al. Safety and efficacy of $90 \mathrm{Y}$ radiotherapy for hepatocellular carcinoma with and without portal vein thrombosis. Hepatology. 2008;47:71-81.

96. Gil-Alzugaray B, Chopitea A, Inarrairaegui M, Bilbao JI, Rodriguez-Fraile M, Rodriguez J, et al. Prognostic factors and prevention of radioembolization-induced liver disease. Hepatology. 2013;57:1078-87.

97. Kennedy A, Nag S, Salem R, Murthy R, McEwan AJ, Nutting C, et al. Recommendations for radioembolization of hepatic malignancies using yttrium-90 microsphere brachytherapy: a consensus panel report from the radioembolization brachytherapy oncology consortium. Int J Radiat Oncol Biol Phys. 2007;68:13-23.

98. Salem R, Thurston KG. Radioembolization with 90yttrium microspheres: a stateof-the-art brachytherapy treatment for primary and secondary liver malignancies. Part 2: special topics. J Vasc Interv Radiol. 2006;17:1425-39.

99. Venkatanarasimha N, Gogna A, Tong KTA, Damodharan K, Chow PKH, Lo RHG, et al. Radioembolisation of hepatocellular carcinoma: a primer. Clinical Radiology. 2017;72:1002-13 
100. Mazzaferro V, Sposito C, Bhoori S, Romito R, Chiesa C, Morosi C, et al. Yttrium-90 radioembolization for intermediate-advanced hepatocellular carcinoma: a phase 2 study. Hepatology. 2013;57:1826-37.

101. Salem R, Lewandowski RJ, Mulcahy MF, Riaz A, Ryu RK, Ibrahim S, et al. Radioembolization for hepatocellular carcinoma using Yttrium-90 microspheres: a comprehensive report of long-term outcomes. Gastroenterology. 2010;138:52-64.

102. Hilgard P, Hamami M, Fouly AE, Scherag A, Muller S, Ertle J, et al. Radioembolization with yttrium-90 glass microspheres in hepatocellular carcinoma: European experience on safety and long-term survival. Hepatology. 2010;52:1741-9.

103. Zhang Y, Li Y, Ji H, Zhao X, Lu H. Transarterial Y90 radioembolization versus chemoembolization for patients with hepatocellular carcinoma: A meta-analysis. Bioscience trends. 2015;9:289-98.

104. Vilgrain V, Pereira H, Assenat E, Guiu B, Ilonca AD, Pageaux GP, et al. Efficacy and safety of selective internal radiotherapy with yttrium-90 resin microspheres compared with sorafenib in locally advanced and inoperable hepatocellular carcinoma (SARAH): an open-label randomised controlled phase 3 trial. Lancet Oncol. 2017;18:1624-36.

105. Chow PKH, Gandhi M, Tan SB, Khin MW, Khasbazar A, Ong J, et al. SIRveNIB: Selective Internal Radiation Therapy Versus Sorafenib in Asia-Pacific Patients With Hepatocellular Carcinoma. J Clin Oncol. 2018;36:1913-21.

106. Boulay BR, Birg A. Malignant biliary obstruction: From palliation to treatment. World J Gastrointest Oncol. 2016;8:498-508.

107. van der Gaag NA, Rauws EA, van Eijck CH, Bruno MJ, van der Harst E, Kubben FJ, et al. Preoperative biliary drainage for cancer of the head of the pancreas. N Engl J Med. 2010;362:129-37.

108. Pisters PW, Hudec WA, Hess KR, Lee JE, Vauthey JN, Lahoti S, et al. Effect of preoperative biliary decompression on pancreaticoduodenectomy-associated morbidity in 300 consecutive patients. Ann Surg. 2001;234:47-55.

109. Namias N, Demoya M, Sleeman D, Reever CM, Raskin JB, Ginzburg E, et al. Risk of postoperative infection in patients with bactibilia undergoing surgery for obstructive jaundice. Surgical infections. 2005;6:323-8.

110. Sohn TA, Yeo CJ, Cameron JL, Pitt HA, Lillemoe KD. Do preoperative biliary stents increase postpancreaticoduodenectomy complications? J Gastrointest Surg. 2000;4:258-67; discussion 67-8

111. Moole H, Bechtold M, Puli SR. Efficacy of preoperative biliary drainage in malignant obstructive jaundice: a meta-analysis and systematic review. World J Surg Oncol. 2016;14:182.

112. Dumonceau JM, Tringali A, Papanikolaou IS, Blero D, Mangiavillano B, Schmid A, et al. Endoscopic biliary stenting: indications, choice of stents, and results: European Society of Gastrointest Endosc (ESGE) Clinical Guideline - Updated October 2017. Endoscopy 2018;50:910-30.

113. Ge PS, Hamerski CM, Watson RR, Komanduri S, Cinnor BB, Bidari K, et al. Plastic biliary stent patency in patients with locally advanced pancreatic adenocarcinoma receiving downstaging chemotherapy. Gastrointest Endosc. 2015;81:360-6.

114. Moss AC, Morris E, Leyden J, MacMathuna P. Do the benefits of metal stents justify the costs? A systematic review and meta-analysis of trials comparing endoscopic stents for malignant biliary obstruction. Eur J Gastroenterol Hepatol. 2007:19:1119-24.

115. Saleem A, Leggett CL, Murad MH, Baron TH. Meta-analysis of randomized trials comparing the patency of covered and uncovered self-expandable metal stents for palliation of distal malignant bile duct obstruction. Gastrointest Endosc. 2011:74:321-7 e1-3.

116. Almadi MA, Barkun A, Martel M. Plastic vs. Self-Expandable Metal Stents for Palliation in Malignant Biliary Obstruction: A Series of Meta-Analyses. Am J Gastroenterol. 2017;112:260-73

117. Dorcaratto D, Hogan NM, Munoz E, Garces M, Limongelli P, Sabater L, et al. Is Percutaneous Transhepatic Biliary Drainage Better than Endoscopic Drainage in the Management of Jaundiced Patients Awaiting Pancreaticoduodenectomy? J Vasc Interv Radiol. 2018:29:676-87.

118. Duan F, Cui L, Bai Y, Li X, Yan J, Liu X. Comparison of efficacy and complications of endoscopic and percutaneous biliary drainage in malignant obstructive jaundice: a systematic review and meta-analysis. Cancer Imaging. 2017;17:27.

119. Guler S, Cimen S, Molinari M. Advances in loco-regional palliation of unresectable cholangiocarcinomas. Ann Palliat Med. 2014;3:65-74.

120. Lidsky ME, Jarnagin WR. Surgical management of hilar cholangiocarcinoma a Memorial Sloan Kettering Cancer Center. Ann Gastroenterol Surg. 2018;2:304-12.

121. Chung YE, Kim MJ, Park YN, Lee YH, Choi JY. Staging of extrahepatic cholangiocarcinoma. Eur Radiol. 2008;18:2182-95.

122. Fang Y, Gurusamy KS, Wang Q, Davidson BR, Lin H, Xie X, et al. Meta-analysis of randomized clinical trials on safety and efficacy of biliary drainage before surgery for obstructive jaundice. Br J Surg. 2013;100:1589-96.

123. Hameed A, Pang T, Chiou J, Pleass H, Lam V, Hollands M, et al. Percutaneous vs. endoscopic pre-operative biliary drainage in hilar cholangiocarcinoma - a systematic review and meta-analysis. HPB (Oxford). 2016;18:400-10.
124. Dumonceau JM, Tringali A, Blero D, Deviere J, Laugiers R, Heresbach D, et al Biliary stenting: indications, choice of stents and results: European Society of Gastrointest Endosc (ESGE) clinical guideline. Endoscopy. 2012;44:277-98

125. Moole H, Dharmapuri S, Duvvuri A, Dharmapuri S, Boddireddy R, Moole V, et al. Endoscopic versus Percutaneous Biliary Drainage in Palliation of Advanced Malignant Hilar Obstruction: A Meta-Analysis and Systematic Review. Can J Gastroenterol Hepatol. 2016;2016:4726078.

126. Rerknimitr R, Kladcharoen N, Mahachai V, Kullavanijaya P. Result of endoscopic biliary drainage in hilar cholangiocarcinoma. J Clin Gastroenterol. 2004;38:51823.

127. Rerknimitr R, Angsuwatcharakon P, Ratanachu-ek T, Khor CJ, Ponnudurai $\mathrm{R}$, Moon JH, et al. Asia-Pacific consensus recommendations for endoscopic and interventional management of hilar cholangiocarcinoma. J Gastroenterol Hepatol. 2013;28:593-607

128. Kerdsirichairat T, Arain MA, Attam R, Glessing B, Bakman Y, Amateau SK, et al. Endoscopic Drainage of $>50 \%$ of Liver in Malignant Hilar Biliary Obstruction Using Metallic or Fenestrated Plastic Stents. Clin Transl Gastroenterol. 2017;8:e115.

129. Fukasawa M, Takano S, Shindo H, Takahashi E, Sato T, Enomoto N. Endoscopic biliary stenting for unresectable malignant hilar obstruction. Clin J Gastroenterol. 2017; 10:485-90.

130. Takahashi E, Fukasawa M, Sato T, Takano S, Kadokura M, Shindo H, et al. Biliary drainage strategy of unresectable malignant hilar strictures by computed tomography volumetry. World J Gastroenterol. 2015;21:4946-53.

131. Maluf-Filho F, de Oliveira JF, Mendonca EQ, Carbonari A, Maciente BA, Salomao BC, et al. II Brazilian consensus statement on endoscopic ultrasonography. Endosc Ultrasound. 2017:6:359-68.

132. Ryu CH, Lee SK. Biliary strictures after liver transplantation. Gut Liver. 2011;5:133-42.

133. Martins FP, De Paulo GA, Conceicao RD, Zurstrassen MP, Thome T, Ferraz-Neto $\mathrm{BH}$, et al. Incidence, risk factors and ERCP outcome for biliary complication after cadaveric OLT. Hepatogastroenterology. 2011;58:732-7.

134. Akamatsu N, Sugawara Y, Hashimoto D. Biliary reconstruction, its complications and management of biliary complications after adult liver transplantation a systematic review of the incidence, risk factors and outcome. Transpl Int 2011;24:379-92.

135. Buxbaum JL, Biggins SW, Bagatelos KC, Ostroff JW. Predictors of endoscopic treatment outcomes in the management of biliary problems after liver transplantation at a high-volume academic center. Gastrointest Endosc. 2011;73:37-44.

136. Shin M, Joh JW. Advances in endoscopic management of biliary complications after living donor liver transplantation: Comprehensive review of the literature. World J Gastroenterol. 2016;22:6173-91.

137. Abdallah AA, Krige JE, Bornman PC. Biliary tract obstruction in chronic pancreatitis. HPB (Oxford). 2007;9:421-8.

138. Carr-Locke DL. Endoscopic therapy of chronic pancreatitis. Gastrointest Endosc. 1999;49:S77-80

139. Catalano MF, Linder JD, George S, Alcocer E, Geenen JE. Treatment of symptomatic distal common bile duct stenosis secondary to chronic pancreatitis comparison of single vs. multiple simultaneous stents. Gastrointest Endosc. 2004;60:945-52.

140. Costamagna G, Pandolfi M, Mutignani M, Spada C, Perri V. Long-term result of endoscopic management of postoperative bile duct strictures with increasing numbers of stents. Gastrointest Endosc. 2001;54:162-8.

141. Costamagna G, Tringali A, Mutignani M, Perri V, Spada C, Pandolfi M, et al Endotherapy of postoperative biliary strictures with multiple stents: results after more than 10 years of follow-up. Gastrointest Endosc. 2010;72:551-7.

142. Morelli G, Fazel A, Judah J, Pan JJ, Forsmark C, Draganov P. Rapid-sequence endoscopic management of posttransplant anastomotic biliary strictures. Gastrointest Endosc. 2008;67:879-85

143. Pasha SF, Harrison ME, Das A, Nguyen CC, Vargas HE, Balan V, et al. Endoscopic treatment of anastomotic biliary strictures after deceased donor liver transplantation: outcomes after maximal stent therapy. Gastrointest Endosc. 2007;66:44-51

144. Tabibian JH, Asham EH, Han S, Saab S, Tong MJ, Goldstein L, et al. Endoscopic treatment of postorthotopic liver transplantation anastomotic biliary strictures with maximal stent therapy (with video). Gastrointest Endosc. 2010;71:505-12.

145. Schwartz DA, Petersen BT, Poterucha JJ, Gostout CJ. Endoscopic therapy of anastomotic bile duct strictures occurring after liver transplantation. Gastrointest Endosc. 2000;51:169-74

146. Zoepf T, Maldonado-Lopez EJ, Hilgard P, Malago M, Broelsch CE, Treichel $\mathrm{U}$, et al. Balloon dilatation vs. balloon dilatation plus bile duct endoprostheses for treatment of anastomotic biliary strictures after liver transplantation. Liver Transpl. 2006;12:88-94. 
147. Cote GA, Slivka A, Tarnasky P, Mullady DK, Elmunzer BJ, Elta G, et al. Effect of Covered Metallic Stents Compared With Plastic Stents on Benign Biliary Stricture Resolution: A Randomized Clinical Trial. Jama. 2016;315:1250-7.

148. Kaffes A, Griffin S, Vaughan R, James M, Chua T, Tee H, et al. A randomized trial of a fully covered self-expandable metallic stent versus plastic stents in anastomotic biliary strictures after liver transplantation. Therap Adv Gastroenterol. 2014; 7:64-71

149. Martins FP, De Paulo GA, Contini MLC, Ferrari AP. Metal versus plastic stents for anastomotic biliary strictures after liver transplantation: a randomized controlled trial. Gastrointest Endosc. 2018;87:131 e1- e13.

150. Poley JW, Lekkerkerker MN, Metselaar HJ, Kuipers EJ, Bruno MJ. Clinical outcome of progressive stenting in patients with anastomotic strictures after orthotopic liver transplantation. Endoscopy. 2013;45:567-70.

151. Tal AO, Finkelmeier F, Filmann N, Kylanpaa L, Udd M, Parzanese I, et al. Multiple plastic stents versus covered metal stent for treatment of anastomotic biliary strictures after liver transplantation: a prospective, randomized, multicenter trial. Gastrointest Endosc. 2017;86:1038-45.

152. Martins FP, Kahaleh M, Ferrari AP. Management of liver transplantation biliary stricture: Results from a tertiary hospital. World journal of Gastrointest Endosc. 2015;7:747-57.

153. Deviere J, Nageshwar Reddy D, Puspok A, Ponchon T, Bruno MJ, Bourke MJ, et al. Successful management of benign biliary strictures with fully covered self-expanding metal stents. Gastroenterology. 2014;147:385-95; quiz e15.

154. Chaput U, Vienne A, Audureau E, Bauret P, Bichard P, Coumaros D, et al. Temporary placement of fully covered self-expandable metal stents for the treatment of benign biliary strictures. United European Gastroenterol J. 2016;4:403-12.

155. Jimenez-Perez M, Melgar Simon JM, Duran Campos A, Gonzalez Grande R, Rodrigo Lopez JM, Manteca Gonzalez R. Endoscopic Management of Post-Liver Transplantation Biliary Strictures With the Use of Fully Covered Metallic Stents. Transplant Proc. 2016:48:2510-4

156. Kahaleh M, Brijbassie A, Sethi A, Degaetani M, Poneros JM, Loren DE, et al. Multicenter trial evaluating the use of covered self-expanding metal stents in benign biliary strictures: time to revisit our therapeutic options? J Clin Gastroenterol. 2013;47:695-9.

157. Tarantino I, Mangiavillano B, Di Mitri R, Barresi L, Mocciaro F, Granata A, et al. Fully covered self-expandable metallic stents in benign biliary strictures: a multicenter study on efficacy and safety. Endoscopy. 2012;44:923-7.

158. Traina M, Tarantino I, Barresi L, Volpes R, Gruttadauria S, Petridis I, et al. Efficacy and safety of fully covered self-expandable metallic stents in biliary complications after liver transplantation: a preliminary study. Liver Transpl. 2009;15:1493-8.

159. Tabibian JH, Asham EH, Goldstein L, Han SH, Saab S, Tong MJ, et al. Endoscopic treatment with multiple stents for post-liver-transplantation nonanastomotic biliary strictures. Gastrointest Endosc. 2009;69:1236-43.

160. Verdonk RC, Buis CI, van der Jagt EJ, Gouw AS, Limburg AJ, Slooff MJ, et al Nonanastomotic biliary strictures after liver transplantation, part 2: Management, outcome, and risk factors for disease progression. Liver Transpl. 2007;13:725-32.

161. Sharma S, Gurakar A, Jabbour N. Biliary strictures following liver transplantation: past, present and preventive strategies. Liver Transpl. 2008;14:759-69.

162. Janssen JJ, van Delden OM, van Lienden KP, Rauws EA, Busch OR, van Gulik $\mathrm{TM}$, et al. Percutaneous balloon dilatation and long-term drainage as treatment of anastomotic and nonanastomotic benign biliary strictures. Cardiovasc Intervent Radiol. 2014:37:1559-67.

163. Fidelman N. Benign Biliary Strictures: Diagnostic Evaluation and Approaches to Percutaneous Treatment. Tech Vasc Interv Radiol. 2015;18:210-7.

164. Nennstiel S, Weber A, Frick G, Haller B, Meining A, Schmid RM, et al. Drainage-related Complications in Percutaneous Transhepatic Biliary Drainage: An Analysis Over 10 Years. J Clin Gastroenterol. 2015;49:764-70.

165. Huszar O, Kokas B, Matrai P, Hegyi P, Petervari E, Vincze A, et al. Meta-Analysis of the Long Term Success Rate of Different Interventions in Benign Biliary Strictures. PloS one. 2017;12:e0169618.

166. Huang P, Zhang H, Zhang XF, Lv W, Lou S. Comparison of Endoscopic Ultrasonography Guided Biliary Drainage and Percutaneous Transhepatic Biliary Drainage in the Management of Malignant Obstructive Jaundice After Failed ERCP. Surg Laparosc Endosc Percutan Tech. 2017;27:e127-e31.

167. Nakai Y, Isayama H, Yamamoto N, Matsubara S, Kogure H, Mizuno S, et al. Indications for endoscopic ultrasonography (EUS)-guided biliary intervention: Does EUS always come after failed endoscopic retrograde cholangiopancreatography? Dig Endosc. 2017;29:218-25.
168. Ogura T, Kitano M, Takenaka M, Okuda A, Minaga K, Yamao K, et al. Multicenter prospective evaluation study of endoscopic ultrasound-guided hepaticogastrostomy combined with antegrade stenting (with video). Dig Endosc. 2018;30:252-9.

169. Martins FP, Ferrari AP. Cholangioscopy-assisted guidewire placement in post-liver transplant anastomotic biliary stricture: efficient and potentially also cost-effective. Endoscopy. 2017;49:E283-E4.

170. Bittencourt PL, Cancado EL, Couto CA, Levy C, Porta G, Silva AE, et al. Brazilian society of hepatology recommendations for the diagnosis and management of autoimmune diseases of the liver. Arq Gastroenterol. 2015;52 Suppl 1:15-46.

171. Stiehl A, Rudolph G, Kloters-Plachky P, Sauer P, Walker S. Development of dominant bile duct stenoses in patients with primary sclerosing cholangitis treated with ursodeoxycholic acid: outcome after endoscopic treatment. J Hepatol. 2002;36:151-6.

172. Tischendorf JJ, Hecker H, Kruger M, Manns MP, Meier PN. Characterization, outcome, and prognosis in 273 patients with primary sclerosing cholangitis: A single center study. Am J Gastroenterol. 2007;102:107-14.

173. Bjornsson E, Olsson R. Dominant strictures in patients with primary sclerosing cholangitis-revisited. Am J Gastroenterol. 2004;99:2281.

174. Berstad AE, Aabakken L, Smith HJ, Aasen S, Boberg KM, Schrumpf E. Diagnostic accuracy of magnetic resonance and endoscopic retrograde cholangiography in primary sclerosing cholangitis. Clin Gastroenterol Hepatol. 2006;4:514-20.

175. Dave M, Elmunzer BJ, Dwamena BA, Higgins PD. Primary sclerosing cholangitis: meta-analysis of diagnostic performance of MR cholangiopancreatography. Radiology. 2010;256:387-96.

176. Lindor KD, Kowdley KV, Harrison ME, American College of G. ACG Clinical Guideline: Primary Sclerosing Cholangitis. Am J Gastroenterol. 2015;110:646-59; quiz 60.

177. Johnson GK, Saeian K, Geenen JE. Primary sclerosing cholangitis treated by endoscopic biliary dilation: review and long-term follow-up evaluation. Curr Gastroenterol Rep. 2006:8:147-55.

178. van Milligen de Wit AW, Rauws EA, van Bracht J, Mulder CJ, Jones EA, Tytgat $\mathrm{GN}$, et al. Lack of complications following short-term stent therapy for extrahepatic bile duct strictures in primary sclerosing cholangitis. Gastrointest Endosc. 1997:46:344-7.

179. Kaya M, Petersen BT, Angulo P, Baron TH, Andrews JC, Gostout CJ, et al. Balloon dilation compared to stenting of dominant strictures in primary sclerosing cholangitis. Am J Gastroenterol. 2001;96:1059-66.

180. Baluyut AR, Sherman S, Lehman GA, Hoen H, Chalasani N. Impact of endoscopic therapy on the survival of patients with primary sclerosing cholangitis. Gastrointest Endosc. 2001;53:308-12.

181. Ginat D, Saad WE, Davies MG, Saad NE, Waldman DL, Kitanosono T. Incidence of cholangitis and sepsis associated with percutaneous transhepatic biliary drain cholangiography and exchange: a comparison between liver transplant and native liver patients. AJR Am J Roentgenol. 2011;196:W73-7.

182. Choi SH, Gwon DI, Ko GY, Sung KB, Yoon HK, Shin JH, et al. Hepatic arterial injuries in 3110 patients following percutaneous transhepatic biliary drainage. Radiology. 2011;261:969-75.

183. Ascher NL. Primary sclerosing cholangitis: liver transplantation or biliary surgery. Liver Transpl Surg. 1995;1:256-7.

184. Burak KW, Rosen CB, Fidler JL, Hesley GK, Nagorney D, Charlton MR, et al. Hypophosphatemia after right hepatectomy for living donor liver transplantation. Can J Gastroenterol. 2004:18:729-33.

185. European Society of Gastrointestinal E, European Association for the Study of the Liver. Electronic address eee, European Association for the Study of the L. Role of endoscopy in primary sclerosing cholangitis: European Society of Gastrointest Endosc (ESGE) and European Association for the Study of the Liver (EASL) Clinical Guideline. J Hepatol. 2017;66:1265-81.

186. Levy MJ, Baron TH, Clayton AC, Enders FB, Gostout CJ, Halling KC, et al. Prospective evaluation of advanced molecular markers and imaging techniques in patients with indeterminate bile duct strictures. Am J Gastroenterol. 2008;103:1263-73.

187. Tischendorf JJ, Kruger M, Trautwein C, Duckstein N, Schneider A, Manns MP, et al. Cholangioscopic characterization of dominant bile duct stenoses in patients with primary sclerosing cholangitis. Endoscopy. 2006;38:665-9.

188. Meining A, Chen YK, Pleskow D, Stevens P, Shah RJ, Chuttani R, et al. Direct visualization of indeterminate pancreaticobiliary strictures with probe-based confocal laser endomicroscopy: a multicenter experience. Gastrointest Endosc. 2011;74:961-8.

189. Olthof SC, Othman A, Clasen S, Schraml C, Nikolaou K, Bongers M. Imaging of Cholangiocarcinoma. Visceral medicine. 2016;32:402-10. 
In article "Recommendations for invasive procedures in patients with diseases of the liver and biliary tract: report of a joint meeting of the Brazilian Society of Hepatology (SBH), Brazilian Society of Digestive Endoscopy (SOBED) and Brazilian Society of Interventional Radiology and Endovascular Surgery (SOBRICE)" published in journal Arquivos de Gastroenterologia, 2019;56(2):213-31, on pages 213 and 231.

Which was read: Joaquim Maurício da Motta Leal Filho

Read: Joaquim Maurício da Motta-Leal-Filho

DOI: dx.doi.org/10.1590/S0004-2803.201900000-42 